\title{
Antiviral and Antimicrobial Nucleoside Derivatives: Structural Features and Mechanisms of Action ${ }^{1}$
}

\author{
A. A. Zenchenko ${ }^{a}$, M. S. Drenichev ${ }^{a}, *$, I. A. Il'icheva ${ }^{a}$, and S. N. Mikhailov ${ }^{a} \dagger$ \\ ${ }^{a}$ Engelhardt Institute of Molecular Biology, Moscow, 119991 Russia \\ *e-mail:mdrenichev@mail.ru
}

Received January 20, 2021; revised April 3, 2021; accepted April 9, 2021

\begin{abstract}
The emergence of new viruses and resistant strains of pathogenic microorganisms has become a powerful stimulus in the search for new drugs. Nucleosides are a promising class of natural compounds, and more than a hundred drugs have already been created based on them, including antiviral, antibacterial and antitumor agents. The review considers the structural and functional features and mechanisms of action of known nucleoside analogs with antiviral, antibacterial or antiprotozoal activity. Particular attention is paid to the mechanisms that determine the antiviral effect of nucleoside analogs containing hydrophobic fragments. Depending on the structure and position of the hydrophobic substituent, such nucleosides can either block the process of penetration of viruses into cells or inhibit the stage of genome replication. The mechanisms of inhibition of viral enzymes by compounds of nucleoside and non-nucleoside nature have been compared. The stages of creation of antiparasitic drugs, which are based on the peculiarities of metabolic transformations of nucleosides in humans body and parasites, have been considered. A new approach to the creation of drugs is described, based on the use of prodrugs of modified nucleosides, which, as a result of metabolic processes, are converted into an effective drug directly in the target organ or tissue. This strategy makes it possible to reduce the general toxicity of the drug to humans and to increase the effectiveness of its action on cells infected by the virus.
\end{abstract}

Keywords: biosynthesis of nucleosides, antibacterial activity, antiviral activity, antiprotozoal activity, RNA viruses, target enzymes, hydrophobic derivatives of nucleosides

DOI: $10.1134 / \mathrm{S} 0026893321040105$

\section{INTRODUCTION}

Rapidly mutating RNA viruses pose a serious threat to humanity. The COVID-19 pandemic caused by the novel severe acute respiratory syndrome coronavirus 2 (SARS-CoV-2) in 2020 exposed a shortage of universal antiviral agents. Viruses are obligate parasites, which genomes encode the minimum set of

\footnotetext{
${ }^{1}$ This review is dedicated to the memory of the Doctor of Chemical Sciences, Professor Sergey Nikolaevich Mikhailov (19492020), an enthusiastic scientist and teacher. The entire scientific life of S.N. Mikhailov was associated with the Institute of Molecular Biology of the Russian Academy of Sciences. From 1995 to 2020 , he headed the laboratory of design and synthesis of biologically active compounds. He made a great contribution to the development of enzymology and nucleoside chemistry. The last years of his life he devoted to the design of new antiviral agents based on nucleosides and their analogs.

Abbreviations: NNRTI, non-nucleoside reverse transcriptase inhibitors; RT, reverse transcriptase; PRPP, 5-phosphoribosyl1-pyrophosphate; CMV, cytomegalovirus; HBV, hepatitis B virus; $\mathrm{HCV}$, hepatitis C virus; HSV, herpes simplex virus; IMPDH, inosine-5'-monophosphate dehydrogenase; MERS-CoV, Middle East respiratory syndrome coronavirus; PfPNP, Plasmodium falciparum purine-nucleosidephosphorylase; RdRp, RNA-dependent RNA polymerase; SARS-CoV, severe acute respiratory syndrome coronavirus; VZV, varicella zoster virus.

${ }^{\dagger}$ Deceased.
}

enzymes and proteins necessary for the replication and assembly of viral particles. For the biosynthesis of building blocks (monomers), cell enzymes are used, so the reproduction of a virus is possible only inside a cell it has infected. There are two main types of antiviral drugs: the first type prevents the penetration of the virus into the cell, the second type disrupts the replication of the viral genome inside the cell. Nucleoside analogs can be active antiviral agents, and the mechanism of their action depends on the type and position of the substituents. The huge interest in the creation of antiviral drugs is not limited to the consideration of classical approaches, and as new technologies appear, new approaches are also being developed [1-5].

Nucleoside-based drugs are also used to treat infectious diseases caused by bacteria, protozoa and fungi. The emergence of drug resistance in pathogenic microorganisms is a serious problem for humanity due to the widespread, not always justified, use of antibiotics. That is why the development of new antimicrobial agents has been, and remains, relevant. In this review, we also discuss the strategy of searching for antiprotozoal compounds for the treatment of socially significant infectious diseases [6-9]. 
Table 1. Concentrations of metabolites involved in the biosynthesis of purine nucleosides ${ }^{\mathrm{a}}$

\begin{tabular}{c|c}
\hline Metabolite & $C^{\mathrm{b}}, \mu \mathrm{M}$ \\
\hline ATP & 2102 \\
GTP & 305 \\
ADP & 137 \\
GDP & 36 \\
AMP & 82 \\
GMP & 32 \\
Ado & 0.5 \\
Guo & 0.9 \\
Ade & 0.4 \\
Gua & 97 \\
\hline
\end{tabular}

a The table summarizes the data presented by T.W. Traut [12].

b Nucleotide concentrations measured in human blood cells, base and nucleoside concentrations measured in extracellular fluid.

The creation of drugs based on natural compounds is a well proven classic approach. To date, about a hundred drugs have been created on the basis of nucleosides, half of which are antiviral and a quarter antitumor [10]. Natural nucleosides have a diverse structure; they are part of nucleotides, DNA, RNA, and coenzymes. More than 140 minor nucleosides were isolated from tRNA, and about 100 disaccharide nucleosides and 200 nucleoside antibiotics, in the structure of which there are additional functional groups and hydrophobic residues, were isolated from various natural sources. The library of natural nucleosides contains about 600 compounds, which serve as the basis for the creation of new biologically active compounds [11].

In this review, the strategies for creating antiviral and antiparasitic drugs are analyzed in the context of the peculiarities of nucleoside metabolism in various organisms. The structural features of nucleoside analogs that determine the mechanism of drug action are considered in details.

\section{Nucleoside Metabolism is the Key to Understanding the Mechanism of Action of Nucleoside Drugs}

Unlike most drugs, nucleosides and their analogs in the human body are first exposed to a number of enzymes of cellular metabolism, which convert them into active forms (nucleotides). The metabolic scheme of various modified nucleosides at the initial stage after entering the body is rather conservative. These compounds usually enter cells and, as a result of enzymatic phosphorylation, are sequentially converted into nucleoside-5'-mono-, di-, and triphosphates (NMP, NDP, and NTP, respectively). These metabolites then inhibit one or more enzymes of DNA or RNA biosynthesis (including viral polymerases). In a cell, the ratio of nucleoside phosphates (NMP : NDP : NTP) is vari- able for different derivatives of nucleosides. It depends on the rate of phosphorylation of the parent nucleoside. The first stage of phosphorylation (NMP formation) is usually rate-limiting and, therefore, the most crucial for activation. In general, the nucleoside equilibrium (N) $\leftrightarrow$ NTP in the cell is shifted towards the formation of triphosphates. It should also be noted that the concentration of NTP in the cell significantly exceeds the concentration of NMP, NDP, and nucleosides involved in metabolic processes necessary for growth, maintenance of vital functions of the organism, and reproduction (Table 1) [12]. These transformations are inseparably linked with the biosynthesis of nucleosides, nucleotides, and nucleic acids in the cell; therefore, knowledge of the peculiarities of nucleotide biosynthesis is the key to understanding the mechanism of action of biologically active nucleoside derivatives.

\section{Nucleoside Biosynthesis Pathways}

Purine and pyrimidine nucleosides and nucleotides (Fig. 1) are synthesized in living organisms-in two ways. The main pathway (de novo) is a complex, multistep and energy-consuming process of the formation of heterocyclic bases in the presence of various donors of carbon and nitrogen, followed by the formation of nucleosides from these bases. An additional pathway for nucleoside biosynthesis, salvage pathways, allows cells to reuse free nitrogenous bases, which are formed as a result of enzymatic cleavage of nucleosides in metabolic processes. This makes nucleoside metabolism more economical.

The key reaction of de novo biosynthesis of purine nucleotides is the formation of phosphoribosylamine (5PRA) as a result of the transfer of the amide group of glutamine to phosphoribosyl pyrophosphate (PRPP) under the action of amidophosphoribosyltransferase (ATase). Next, a purine heterocyclic base is assembled based on 5PRA with the participation of various carbon and nitrogen donors to form inosine-5'-monophosphate (IMP), a metabolic precursor of purine nucleotides. IMP is metabolized to AMP and GMP through the formation of intermediates: adenylosuccinate (sAMP) and xanthosine monophosphate (XMP), followed by phosphorylation by specific nucleosidemonophosphate and nucleoside diphosphate-kinases to active triphosphate forms (ATP and GTP) [13] (see "Purine biosynthesis", Fig. 1).

In contrast to the synthesis of purines, the pyrimidine heterocyclic base is initially synthesized from glutamine, $\mathrm{CO}_{2}$ and ATP with the formation of carbamoyl phosphate. During the series of transformations, orotic acid, formed from carbamoyl phosphate, binds to ribose 5'-phosphate under the action of orotate phosphoribosyltransferase with the formation of orotidine 5'-monophosphate (OMP), the initial substrate for the de novo biosynthesis of pyrimidine nucleotides (see Fig. 1). Further decarboxylation leads to the for- 


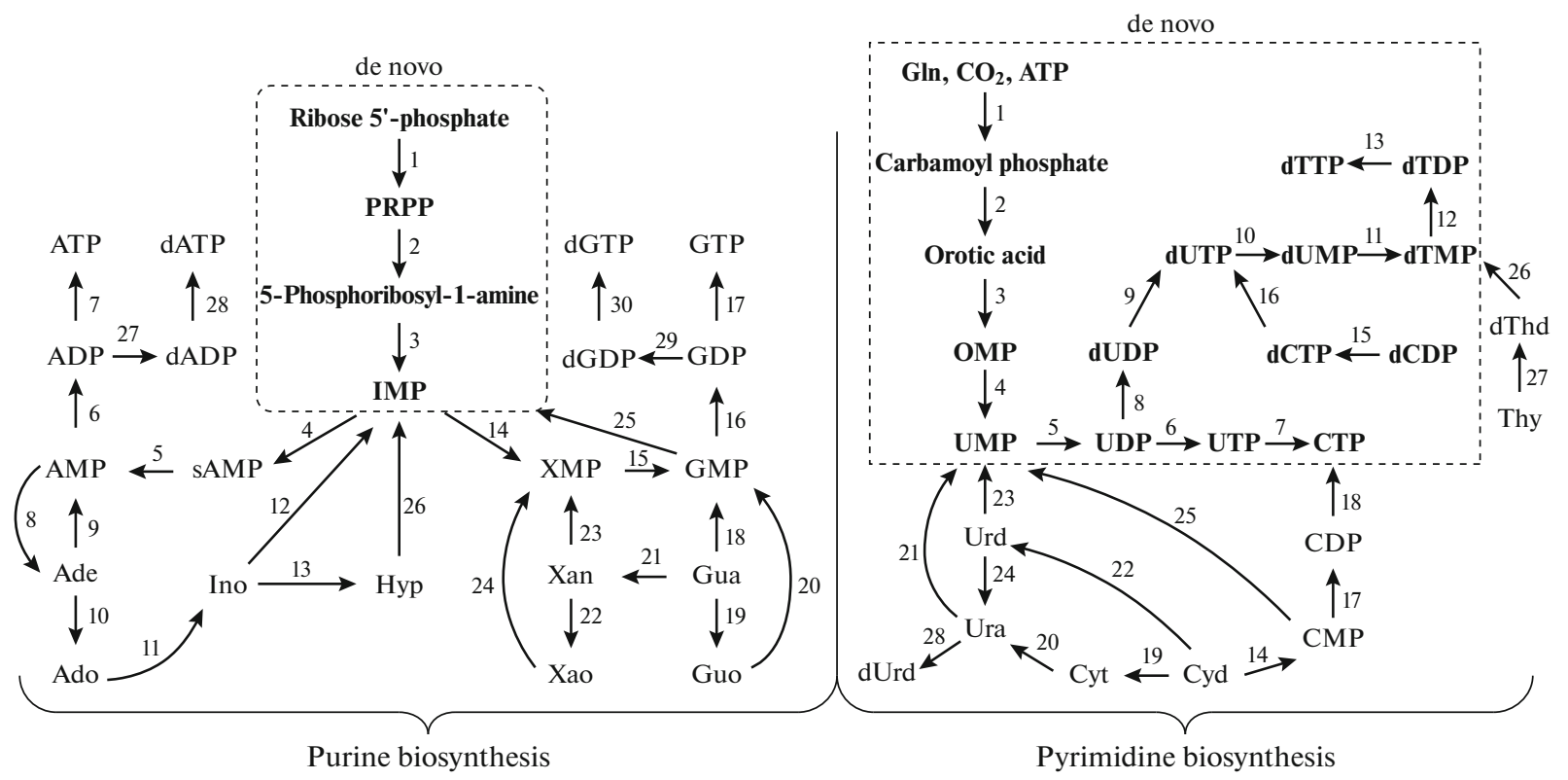

Fig. 1. Biosynthesis of purine and pyrimidine nucleosides/nucleotides. Enzymes are indicated by numbers. Purine biosynthesis: (1) phosphoribosyl pyrophosphate synthetase (EC 2.7.6.1); (2) amidophosphoribosyltransferase (EC 2.4.2.14); (3) phosphoribosylamine-glycine ligase (EC 6.3.4.13), phosphoribosylglycinamide formyltransferase (EC 2.1.2.2), phosphoribosylformylglycinamidine synthetase (EC 6.3.5.3), phosphoribosylformylglycinamidine cyclo-ligase (EC 6.3.3.1), phosphoribosylaminoimidazole carboxylase (EC 4.1.1.21), 5-(carboxyamino)imidazole ribonucleotide mutase (EC 5.4.99.18), phosphoribosylaminoimidazolesuccinocarboxamide synthetase (EC 6.3.2.6), adenylosuccinate lyase (EC 4.3.2.2), phosphoribosylaminoimidazolecarboxamideformyltransferase (EC 2.1.2.3); (4) adenylosuccinate synthetase (EC 6.3.4.4); (5) adenylosuccinate lyase (EC 4.3.2.2); (6) adenylate kinase (EC 2.7.4.3); (7) nucleoside diphosphate kinase (EC 2.7.4.6); (8) adenylate nucleosidase (EC 3.2.2.4); (9) adenine phosphoribosyltransferase (EC 2.4.2.7); (10) purine nucleoside phosphorylase (EC 2.4.2.1); (11) adenosine deaminase (EC 3.5.4.4); (12) guanosine-inosine kinase (EC 2.7.1.73); (13) purine nucleoside phosphorylase (EC 2.4.2.1); (14) inosine-5'-monophosphate dehydrogenase (EC 1.1.1.205); (15) guanylate synthetase (EC 6.3.5.2); (16) guanylate kinase (EC 2.7.4.8); (17) nucleoside diphosphate kinase (EC 2.7.4.6); (18) hypoxanthine guanine phosphoribosyltransferase (EC 2.4.2.8); (19) purine nucleoside phosphorylase (EC 2.4.2.1); (20) guanosine-inosine kinase (EC 2.7.1.73); (21) guanine deaminase (EC 3.5.4.3); 22) purine nucleoside phosphorylase (EC 2.4.2.1); (23) xanthine-guanine phosphoribosyltransferase (EC 2.4.2.22); (24) guanosine-inosine kinase (EC 2.7.1.73); (25) guanosine-5'-monophosphate reductase (EC 1.7.1.7); (26) hypoxanthine-guanine phosphoribosyltransferase (EC 2.4.2.8); (27) ribonucleoside diphosphate reductase (EC 1.17.4.1); (28) nucleoside diphosphate kinase (EC 2.7.4.6); (29) ribonucleoside diphosphate reductase (EC 1.17.4.1); (30) nucleoside diphosphate kinase (EC 2.7.4.6). Pyrimidine biosynthesis: (1) carbamoyl phosphate synthase (EC 6.3.5.5); (2) aspartate carbamoyltransferase (EC 2.1.3.2), dihydroorotase (EC 3.5.2.3), dihydroorotate dehydrogenase (EC 1.3.99.11); (3) orotate phosphoribosyltransferase (EC 2.4.2.10); (4) orotidine 5'-phosphate decarboxylase (EC 4.1.1.23); (5) uridylate kinase (EC 2.7.4.22); (6) nucleoside diphosphate kinase (EC 2.7.4.6); (7) cytidine 5 '-triphosphate synthase (EC 6.3.4.2); (8) ribonucleoside diphosphate reductase (EC 1.17.4.1); (9) nucleoside diphosphate kinase (EC 2.7.4.6); (10) deoxyuridine triphosphate (dUTP) diphosphatase (EC 3.6.1.23); (11) thymidylate synthase (EC 2.1.1.45); (12) thymidylate kinase (EC 2.7.4.9); (13) nucleoside diphosphate kinase (EC 2.7.4.6); (14) uridine-cytidine kinase (EC 2.7.1.48); (15) nucleoside diphosphate kinase (EC 2.7.4.6); (16) deoxycytidine triphosphate (dCTP) deaminase (EC 3.5.4.13); (17) cytidylate kinase (EC 2.7.4.14); (18) nucleoside diphosphate kinase (EC 2.7.4.6); (19) nucleoside hydrolase (EC 3.2.2); (20) cytosine deaminase (EC 3.5.4.1); (21) uracil phosphoribosyltransferase (EC 2.4.2.9); (22) cytidine deaminase (EC 3.5.4.5); (23) uridinecytidine kinase (EC 2.7.1.48); (24) uridine phosphorylase (EC 2.4.2.3); (25) cytidine deaminase (EC 3.5.4.5); (26) thymidine kinase (EC 2.7.1.21); (27) thymidine phosphorylase (EC 2.4.2.4); (28) thymidine phosphorylase (EC 2.4.2.4). Abbreviations: PRPP, phosphoribosyl pyrophosphate; IMP, inosine monophosphate; OMP, orotidine 5'-monophosphate; sAMP, adenylosuccinate; XMP, xanthosine-5'-monophosphate; Xao, xanthosine, Xan, xanthine; Thy, thymine; Thd, thymidine, Hyp, hypoxanthine. A simplified scheme of biosynthesis was compiled on the basis of data on metabolic transformations of nucleosides/nucleotides [12-14].

mation of an intermediate biosynthesis product, uridine-5'-monophosphate (UMP), which, as a result of sequential phosphorylation, is converted into active uridine-5'-triphosphate (UTP). UTP is involved in the formation of cytidine-5'-triphosphate (CTP) under the action of cytidine-5'-triphosphate synthase, which catalyzes the amidation of UTP by ATP-dependent exchange reaction of the ketone group of uracil with the amide group of glutamine [13, 14].
Deoxyribonucleotides (dATP, dGTP, and dCTP) included in DNA are formed de novo from ribonucleoside-5'-diphosphates under the action of ribonucleoside-diphosphate reductases and nucleoside-diphosphate kinases (Fig. 1). Thymidine 5'-triphosphate (dTTP) is formed in a series of enzymatic reactions including the conversion of deoxyuridine 5'-triphosphate (dUTP) to deoxyuridine-5'-monophosphate (dUMP) by deoxyuridine triphosphatase, methylation 
of dUMP to dTMP catalyzed by the thymidylate synthase, and sequential phosphorylation of dTMP by nucleotide kinases. Most of the dUTP (about 75\%) used for dTTP synthesis is formed as a result of dCTP deamination by deoxycytidine triphosphate deaminase, rather than directly from UDP under the action of ribonucleotide reductase and nucleoside diphosphate-kinase [13].

The "re-utilization" pathway of biosynthesis is based on the attachment of the PRPP molecule to the free nitrogenous base (formed as a result of the decomposition of nucleic acids and subsequent enzymatic cleavage of nucleotides), meanwhile the PRPP-dependent phosphoribosylation of purines is catalyzed by adenine phosphoribosyltransferase, which is responsible for the formation of AMP from adenine, and hypoxanthine-guanine phosphoribosyltransferase (HGPRT), which catalyzes the formation of IMP and GMP from hypoxanthine and guanine, respectively. For the reutilization pathway, one of the main stages, accompanied by phosphorolysis, is the cleavage of the $N$-glycosidic bond of purine nucleosides by purine nucleoside phosphorylase, and pyrimidine nucleosides, by pyrimidine nucleoside phosphorylase and uridine phosphorylase. All these enzymes catalyze the reversible cleavage of the glycosidic bond of the corresponding ribo- and deoxyribonucleosides in the presence of inorganic phosphate with the formation of a heterocyclic base and ribose/deoxyribose-1-phosphate. The thermodynamic equilibrium of reactions is shifted towards the synthesis of nucleosides [15], and this is more significant in the case of purine nucleosides [16]. The key enzyme for the phosphorolysis of pyrimidine nucleosides is uridine phosphorylase, which catalyzes the reversible cleavage of uridine, 2'-deoxyuridine and thymidine to the corresponding heterocyclic bases and ribose-1-phosphate. Further conversion of nucleosides to nucleotides is catalyzed by uridine-cytidine kinase, which phosphorylates uridine and cytidine to 5 '-monophosphate forms with equal efficiency [17].

An additional biosynthetic pathway for pyrimidine deoxyribonucleotides consists in the phosphorylation of thymidine to dTMP by thymidine kinase. The phosphorolytic cleavage of deoxyuridine and thymidine by thymidine phosphorylase also plays a key role; in this case, the thermodynamic equilibrium is shifted towards the formation of nucleosides [13].

Thus, the metabolism of nucleosides/nucleotides is a complex multistep process that includes a large set of enzymes and reactions that convert nucleotides, nucleosides, and nitrogenous bases. Possessing structural similarity to natural substrates, drug compounds of a nucleoside nature can affect different stages of nucleoside biosynthesis.

\section{The Main Differences in de novo Biosynthesis of Nucleosides in Different Organisms. The Principles of Creating Antiparasitic Drugs}

All living organisms of all three domains, bacteria, archaea, and eukaryotes, have de novo purine and pyrimidine biosynthesis [18]. The pathways of biosynthesis in bacteria and eukaryotes are practically the same, while in archaea they differ [19]. In the genomes of bacteria and archaea, clusters of genes encoding de novo biosynthetic enzymes are organized differently $[20,21]$. The regulation of transcription of these genes also differs $[19,20]$. But the enzymes involved in biosynthesis are the same in bacteria and archaea, while a number of enzymes of de novo biosynthesis differ in some eukaryotes [18]. Thus, in the yeast Saccharomyces cerevisiae, the active sites of carbamoyl phosphate synthetase (CPSase; EC 6.3.5.5) and aspartate carbamoyltransferase (ATCase; EC 2.1.3.2) are incorporated into the total polypeptide chain, which also contains an inactive variant of dihydroorotase (DHOase; EC 3.5.2.3). For pyrimidine biosynthesis, mammalian cells use a trifunctional protein, dihydroorotate synthetase, which contains three active centers in one polypeptide chain, which alternately perform the functions of CPSase, ATCase, and DHOase $[18,20]$, and a bifunctional protein, in the polypeptide chain of which are the active sites of orotate phosphoribosyltransferase (EC 2.4.2.10) and orotodin 5'-phosphate decarboxylase (OMPdecase; EC 4.1.1.23) [20]. Enzymes of pyrimidine biosynthesis in lower eukaryotes are located in mitochondria, and in mammals, in the cytosol of cells $[18,20]$, which ensures the maximum compactness of the reaction space during de novo synthesis in mammalian cells. In cells $95 \%$ of de novo biosynthesis is provided by IMP and UMP [18]. Viruses and phages, as infectious agents that reproduce only in living cells, use in their infectious cycle nucleosides/nucleotides synthesized by the host [22].

During evolution, some organisms lost some of the genes necessary for purine or pyrimidine synthesis de novo. These are auxotrophs, their existence is possible only if there are purine/pyrimidine derivatives in the nutrient medium. They can parasitize in other organisms, in particular in the human body, causing various diseases. The re-utilization pathway of nucleoside biosynthesis is of key importance for them. Consequently, enzymes catalyzing reactions of an additional pathway of nucleotide metabolism (among them nucleoside phosphorylases) can be considered as targets for the creation of antibacterial and antiprotozoal drugs [23-26]. Purine auxotrophs include such organisms as the helminth Schistosoma mansoni, which causes an endemic disease in humans, schistosomiasis [25, 26], and the malaria plasmodium, Plasmodium falciparum, which is the causative agent of a severe form of malaria [23, 24]. The pyrimidine auxotrophs include the flagellar protist Giardia lamblia [27-29], which can parasitize in the small intestine of 
<smiles>O=c1[nH]cnc2c(C3NC(CO)C(O)C3O)c[nH]c12</smiles>

$\mathrm{ImmH}$<smiles></smiles>

5'-MT-ImmH<smiles>Nc1nc2c(C3NC(CO)C(O)C3O)c[nH]c2c(=O)[nH]1</smiles>

ImmG<smiles>Nc1nc2c(CN3CC(O)[C@H](O)C3)c[nH]c2c(=O)[nH]1</smiles>

DADMe-ImmG

Fig. 2. Structures of immunicillins.

mammals and birds, causing giardiasis. The search for effective and highly specific inhibitors of nucleoside phosphorylases is one of the strategies for creating drugs for the treatment of diseases caused by these parasites. Certain results have already been achieved on this path. Derivatives of immunicillin were studied in detail (Fig. 2), the conformation of which is close to the assumed transitional conformation of the substrate of purine nucleoside phosphorylases [30, 31]. Earlier reported that 5'-methylthio-immucillin-H_(5'-MT-ImmH) binds to the purine nucleoside phosphorylase (PfPNP) of Plasmodium falciparum 112 times more efficiently than to the purine nucleoside phosphorylase of human erythrocytes ( $K_{\mathrm{d}} 2.7$ and $303 \mathrm{nM}$, respectively). This is most likely due to the different structure of the active sites of these two purine nucleoside phosphorylases [31]. 5'-MT-ImmH has been proposed as a PfPNP inhibitor for the treatment of malaria in humans [9, 31, 32]. Another immunicillin derivative, DADMeImmucillin-G (BCX4945), is currently in preclinical trials. It has already been demonstrated to be highly effective in treating malaria in a monkey model [33]. The structure of its complex with purine nucleoside phosphorylase of human erythrocytes was studied using NMR spectroscopy [34].

\section{MECHANISM OF ANTI-VIRAL ACTION OF NUCLEOSIDES}

\section{Polymerase Inhibitors}

The mechanism of biological activity of most antiviral drugs based on nucleosides and their analogs is associated with their intracellular transformation into 5'-mono-, di- and triphosphates under the action of viral and cellular kinases with subsequent inclusion of triphosphates into nucleic acids, which leads to inhibition of viral genome replication [3]. The genome of a virus encodes a number of proteins and enzymes necessary for the multiplication of the virus in the infected cell, while maintenance of the life cycle of a virus is carried out through the metabolic pathways of the host cell with the involvement of the corresponding enzymes.

The viral enzymes involved in the replication of viral nucleic acids are RNA-dependent RNA polymerase (RNA-containing viruses), RNA-dependent DNA polymerase (retroviruses), and DNA-dependent DNA polymerase and DNA-dependent RNA polymerase for DNA containing viruses. Herpes simplex viruses (HSV), in addition to DNA polymerase as the main replication enzyme, encode thymidine kinase, which carries out 5'-monophosphorylation of nucleosides and their analogs in the cell [35]. Viral enzymes are usually less specific than the enzymes of the host cell, which leads to a high rate of viral reproduction and the rapid development of drug resistance.

The action of nucleosides and their analogs can be aimed at inhibiting the synthesis of viral nucleic acids, increasing the frequency of lethal mutations of viral genomes (lethal mutagenesis) and other possible mechanisms of action aimed at inhibiting the biosynthesis of nucleosides [4]. In viruses, enzymes that differ from cellular enzymes are involved in the synthesis of nucleic acids these are: DNA-dependent DNA polymerase, RNA-dependent DNA polymerase (reverse transcriptase, RT), and RNA-dependent 

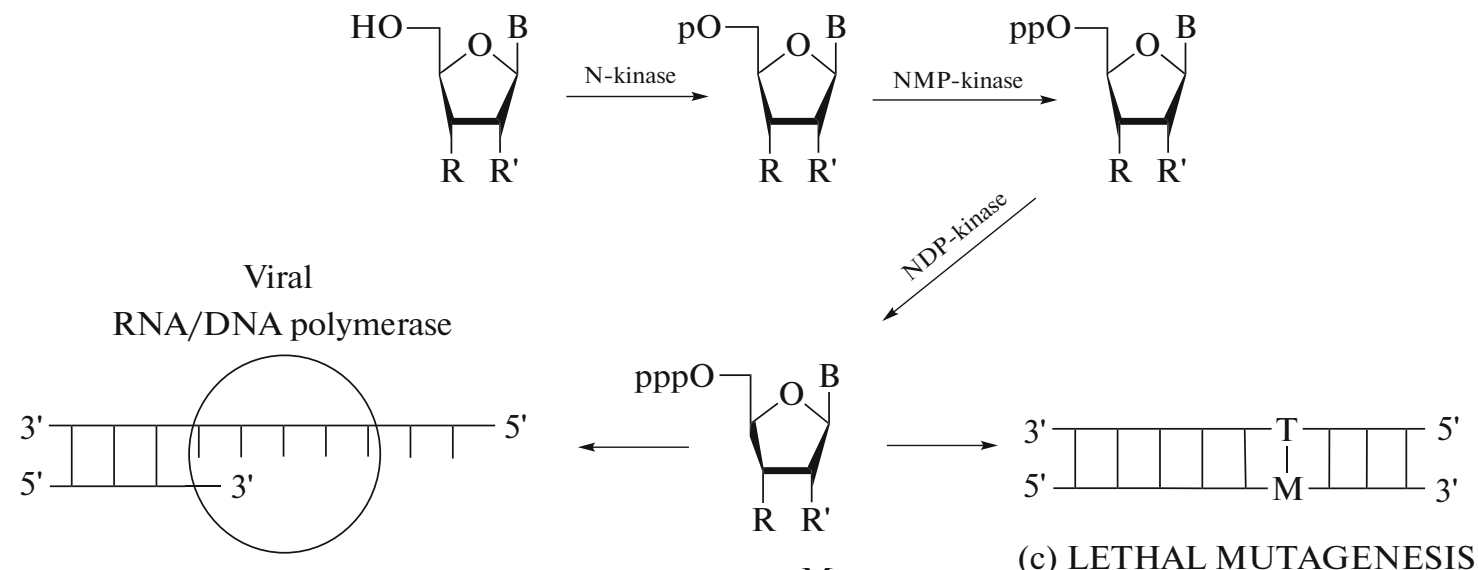

(a) RNA/DNA POLYMERASE INHIBITOR (inhibition of pppN incorporation)

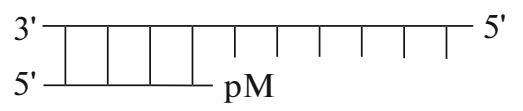

(b) RNA/DNA STRAND GROWTH TERMINATOR (absence of the $3^{\prime} \mathrm{OH}$ group in pppM)

pppM

(c) LETHAL MUTAGENESIS
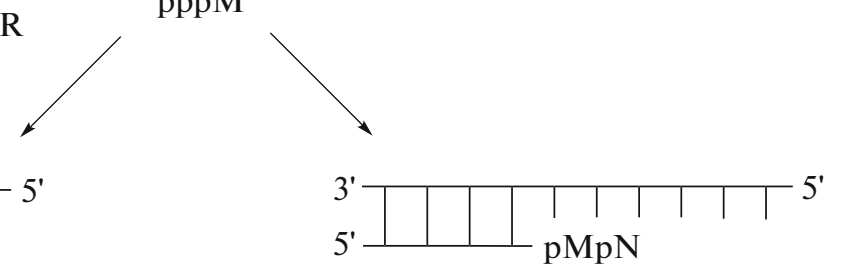

(d) KINETIC TERMINATOR

(single/multiple insertion of pppM into the growing chain reduces the rate of incorporation of pppN, leading to the termination of NA synthesis)

Fig. 3. The main mechanisims of action of nucleoside drugs on the synthesis of viral RNA/DNA. The triphosphate form of a nucleoside analog can act as an RNA/DNA polymerase inhibitor (a), an RNA/DNA chain growth terminator (b), a kinetic terminator (c), and by the mechanism of lethal mutagenesis (d). Abbreviations: N-kinase, nucleoside kinase; NA, nucleic acid; $\mathrm{M}$, mutation; pppM, nucleoside 5'-triphosphate analog; pppN, natural nucleoside 5'-triphosphate; $\mathrm{B}$, heterocyclic base; $\mathrm{R}=\mathrm{H}$, $\mathrm{OH} ; \mathrm{R}^{\prime}=\mathrm{H}, \mathrm{OH}$.

RNA polymerase. Nucleoside analogs in the form of NTP are aimed at suppressing viral RNA / DNA synthesis in various ways, which are shown in Fig. 3.

Any modified nucleoside 5'-triphosphate can inhibit the synthesis of nucleic acids either as a competitive inhibitor of the incorporation of natural NTP into the growing nucleic acid chain (Fig. 3a), or as a terminator of chain growth due to the incorporation of nucleoside 5 '-triphosphate not containing a hydroxyl group in the 3'-position, into the growing RNA/DNA strand (Fig. 3b). Nucleoside-5'-triphosphates containing a sterically inaccessible for the enzymatic reaction hydroxyl group in the 3 '-position can also act as terminators of chain growth. For example, 3'-methylUTP, which is the termination substrate of Escherichia coli RNA polymerase, can be used for nucleic acid sequencing. In this compound, the 3'-methyl group, which replaces the proton, significantly reduces the reactivity of the 3 -hydroxyl group [36, 37].

Kinetic termination of the growth of the nucleic acid chain is also possible: in this case the modified nucleoside 5'-triphosphate can be incorporated into the growing chain, but the rate of its incorporation and subsequent chain elongation are greatly slowed down in comparison with natural NTP. Kinetic termination can be caused by intramolecular or intermolecular sterically nonoptimal interactions of the enzyme with modified nucleoside 5'-triphosphate, as well as disruption of the hydrogen bonds between the matrix and primer (Fig. 3d). As a result, the synthesis of the nucleic acid chain stops. This phenomenon was first described in the late 1980s into the 90s [37-39]. Under the conditions of a single-substrate reaction, when the $D$-allo-diastereomer or $L$-talo-diastereomer of 5'-methylUTP (5'-aMe-UTP and 5'-tMe-UTP) was added to the presynthesized primer RNA together with natural UTP, 5'-aMe-UTP was incorporated approximately 100 times less efficiently, and 5'-tMe-UTP was incorporated 1000 times less efficiently than the natural substrate of UTP $[38,39]$. In the absence of UTP, a natural substrate of RNA polymerase, no more than two 5'-C-methyluridine residues were attached to the presynthesized RNA in this case, that is, the efficiency of the subsequent incorporation of analogs decreased even more compared to the conditions in which the 
mixture of UTP and 5'-aMe-UTP or 5'-tMe-UTP was added to the enzyme [38, 39].

Another mechanism of antiviral activity of nucleoside-based compounds is lethal mutagenesis. Mutations upon the inclusion of a modified nucleoside in the RNA/DNA chain can lead to the formation of non-viable virus strains (Fig. 3c) [40]. In addition, the presence of modified nucleosides in the cell, as well as the corresponding NMP, NDP, and NTP, can inhibit the biosynthesis of nucleic acids by changing the concentrations of natural NMP, NDP, and NTP and their ratios. The main mechanisms of action of a number of known drugs are discussed below.

Most of the nucleoside/nucleotide analogs of drugs used as antiviral agents act as inhibitors and terminators of DNA or RNA synthesis [2, 5].

The clinically approved drugs acyclovir, ganciclovir, and penciclovir (Table 2), which are acyclic analogues of nucleosides, as well as their prodrugs that increase oral bioavailability (valacyclovir, valganciclovir and famciclovir), are active against DNA-containing viruses: Herpes simplex viruses (HSV) and Cytomegaloviruses (CMV) [1]. These drugs inhibit HSV and CMV polymerases and terminate replication by acting in the form of triphosphates. The genomes of viruses of the Herpesviridae family encode a number of enzymes of nucleic acid metabolism: thymidine kinase, thymidylate synthase, deoxyuridine triphosphatase, and ribonucleotide reductase [35]. Of greatest interest, from the point of view of intracellular activation of nucleosides and their analogs, is thymidine kinase, which catalyzes the first, rate-limiting step: monophosphorylation. Thymidine kinase of HSV does not belong to highly specific enzymes; therefore, it can phosphorylate not only thymidine, but also purine nucleoside analogs. Acyclovir and penciclovir, medicines approved by the US Food and Drug Administration (FDA) for the treatment of HSV, are phosphorylated by viral thymidine kinases after penetration into the cell to the corresponding monophosphates [41-45]. Subsequent two-step phosphorylation by the host cell enzymes guanylate kinase and nucleoside-diphosphate kinase, leads to the formation of their triphosphorylated forms, which compete with the natural substrate, dGTP, for incorporation into DNA blocking its synthesis [41]. Ganciclovir-5'-triphosphate and valganciclovir-5'-triphosphate are incorporated into viral DNA and block viral replication, working as kinetic terminators [43].

The purine nucleoside analog, vidarabine (Table 2), targeting HSV and varicella-zoster virus (VZV), in the active 5'-triphosphate form stops viral DNA replication by competitive inhibition of viral DNA polymerase, replacing dATP [46].

It should be noted that along with the main mechanism of action of nucleoside analogs, other pathways and targets are known (ribonucleoside reductase, RNA polyadenylation, and S-adenosyl homocysteine hydrolase) [43]. The mechanism of the antiviral action of 2'-deoxyuridine analogs (idoxuridine, trifluridine; Table 2) has not been studied in details. It is assumed that these compounds inhibit the DNA synthesis of herpes viruses. After mono-phosphorylation with specific viral thymidine kinases and then cellular kinases to 5'-triphosphate forms, these drugs compete with dTTP for insertion into viral DNA [47]. After monophosphorylation with viral thymidine kinases, 5-(trifluoromethyl)-2'-deoxyuridine-5'-monophosphate irreversibly inhibits thymidylate synthase, and its triphosphate competes with dTTP for incorporation into the DNA strand synthesized by DNA polymerase [43]. The mechanism of action of another analogue of 2'-deoxyuridine, brivudine (the drug is approved for the treatment of the herpes virus in a number of European countries), is kinetic termination of the DNA synthesis of HSV-1 and VZV [47-50].

Acyclic nucleoside phosphonate analogs (cidofovir, adefovir dipivoxil, tenofovir disoproxil fumarate; Table 2) also act as viral replication terminators, whose mechanism of action is based on the presence of a phosphonate bond ( $-\mathrm{PC}-$ ) instead of the usual phosphate bond (-POC-). This is a characteristic feature of nucleotide analogs active against CMV polymerases, HIV, and hepatitis B virus (HBV) [51]. These drugs are initially phosphorylated by cellular kinases to phosphono-diphosphate forms, since their phosphonate group mimics 5'-monophosphate in nucleotides. As in the case of other modified nucleoside 5'-triphosphates, they competitively inhibit the incorporation of the natural substrate into the growing DNA strand and, as a consequence, the activity of DNA polymerase. The phosphonate bond, in contrast to the phosphate bond, cannot be cleaved by phosphodiesterase, which ensures the high stability of these compounds in the cell $[52,53]$.

The drugs adefovir and tenofovir are able to bypass the first limiting stage of phosphorylation in the intracellular metabolism of nucleoside analogs. In diphosphorylated forms, adefovir and tenofovir act as alternative substrates and chain terminators in the DNA synthesis reaction catalyzed by HIV reverse transcriptase (HIV RT) [54-56]. The inhibitory effect of adefovir and tenofovir on HBV replication may be related to the termination of viral DNA chain growth in the presence of RT. Adefovir and tenofovir in the diphosphate form apparently have higher affinity for HIV RT (and HBV RT) than for cellular DNA polymerases $\alpha$, $\beta, \gamma, \delta$, and $\varepsilon[57,58]$, and this may explain their selectivity to retroviruses and hepadnaviruses.

All nucleoside HIV RT inhibitors, known as 2',3'-dideoxynucleoside analogs (zidovudine, didanosine, zalcitabine, stavudine, lamivudine, abacavir, emtricitabine; Table 2), in the form of 5'-triphosphates terminate viral DNA synthesis. Their mechanism of action is to compete with natural substrates for incorporation into viral DNA synthesized by HIV RT. Once incor- 

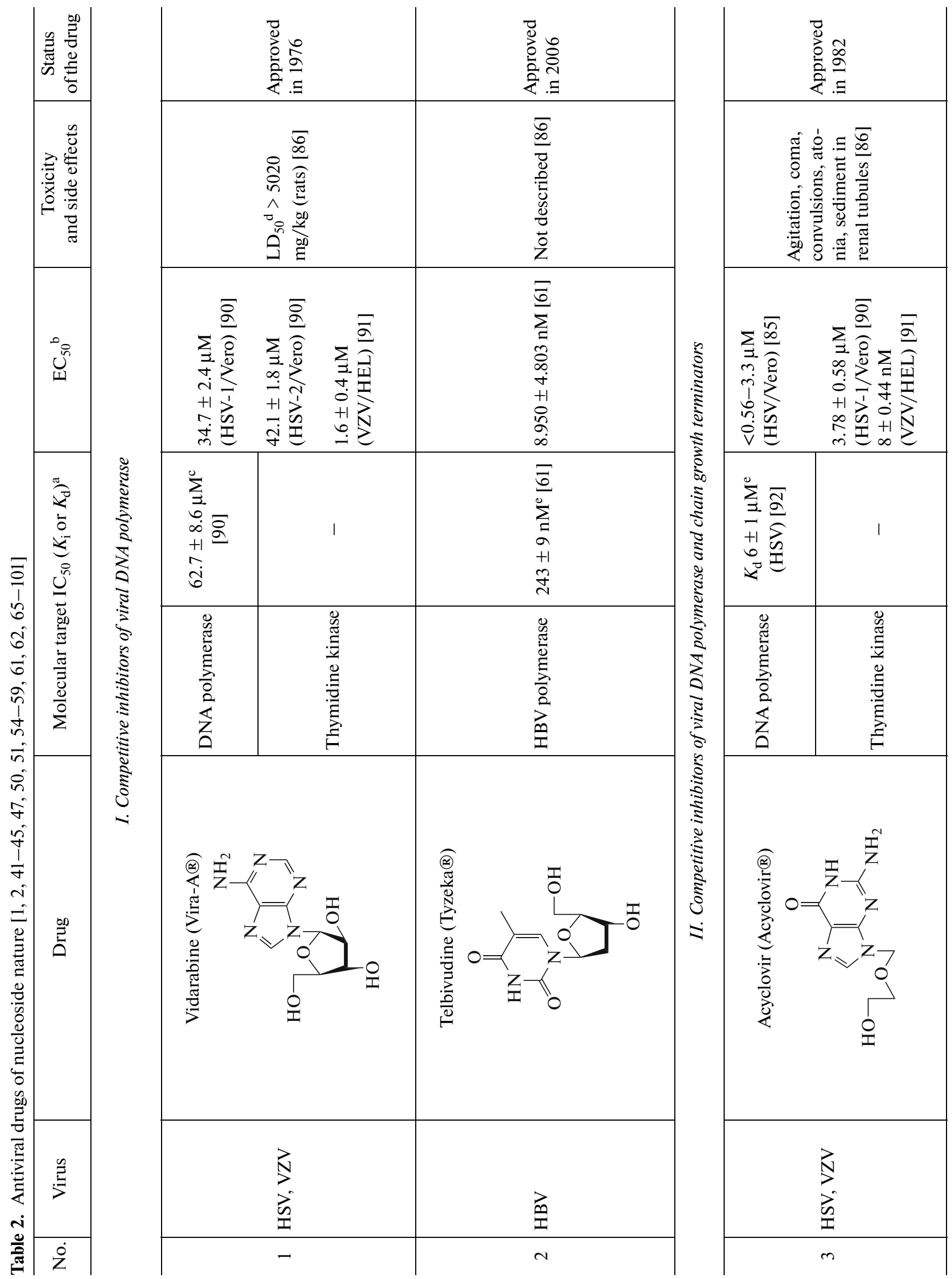


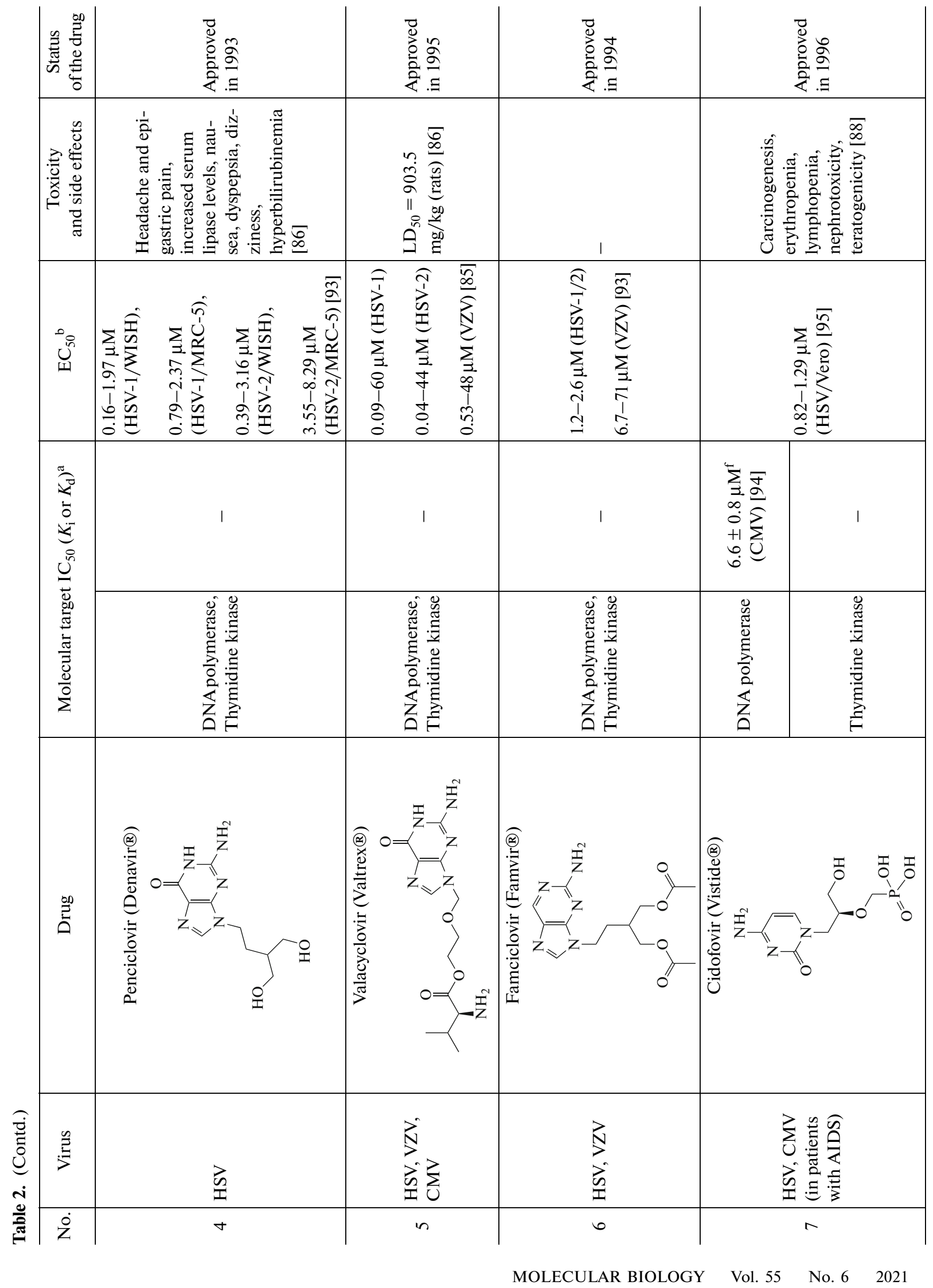



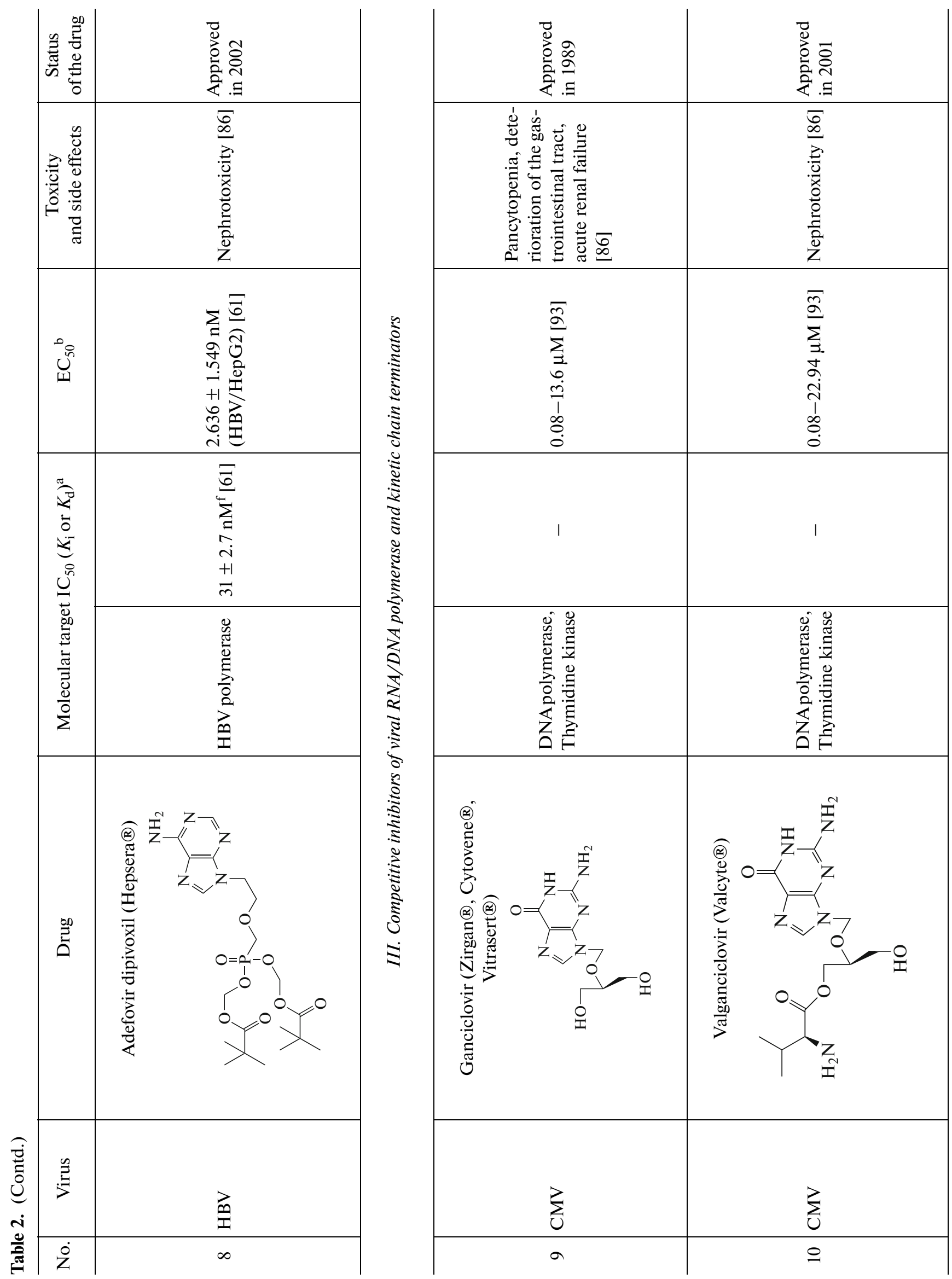


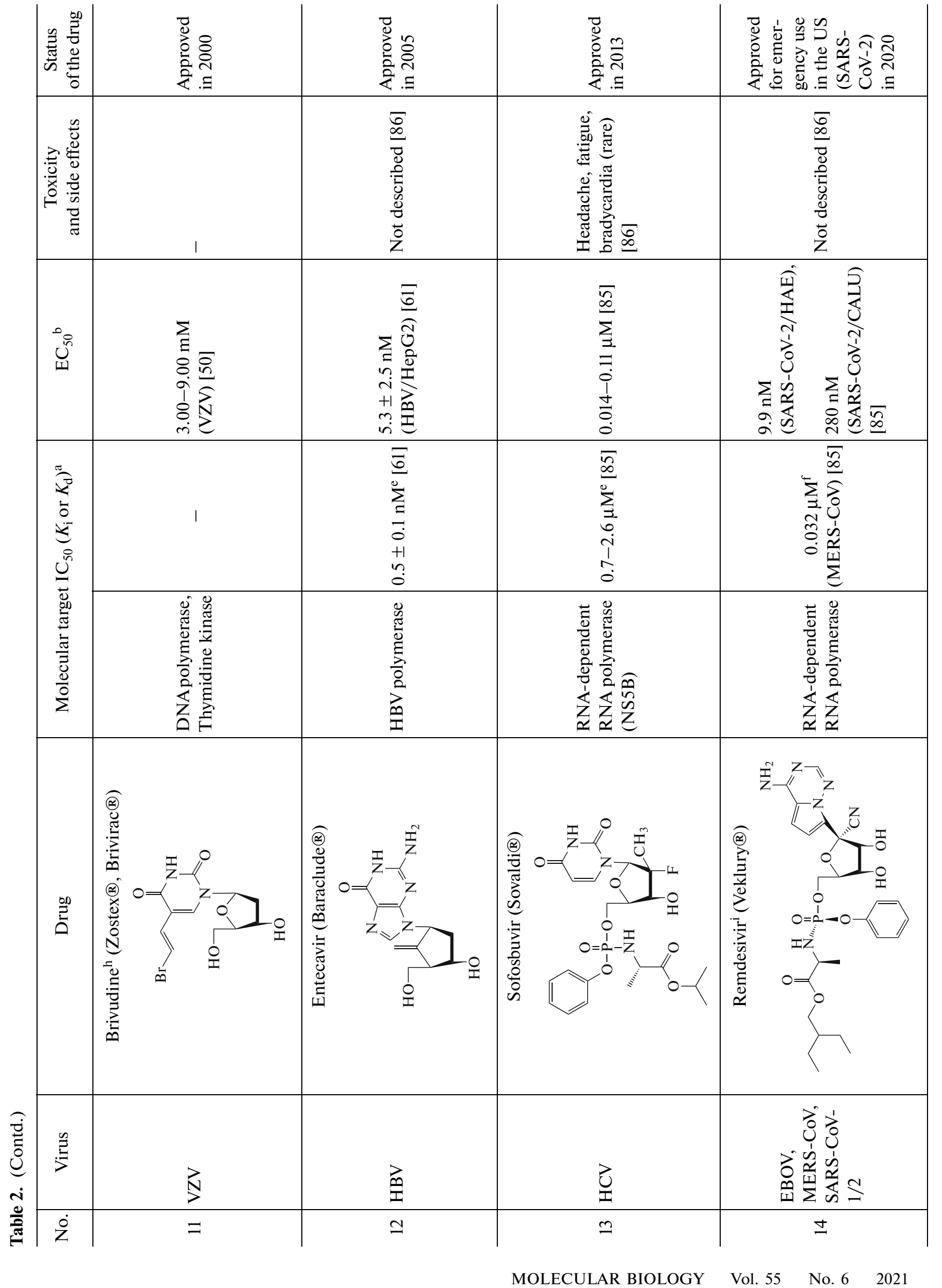




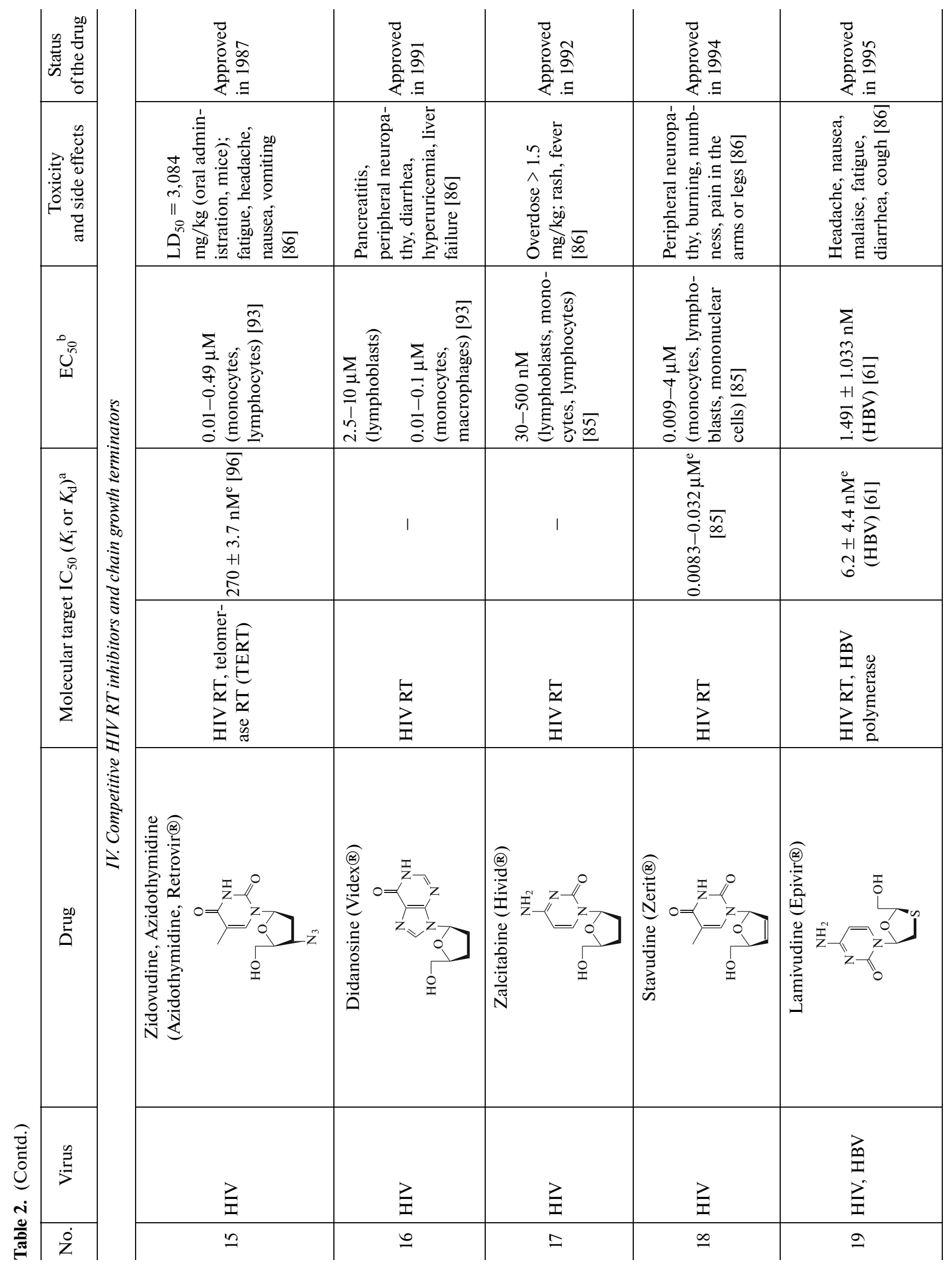

MOLECULAR BIOLOGY Vol.55 No. $6 \quad 2021$ 
ZENCHENKO et al.

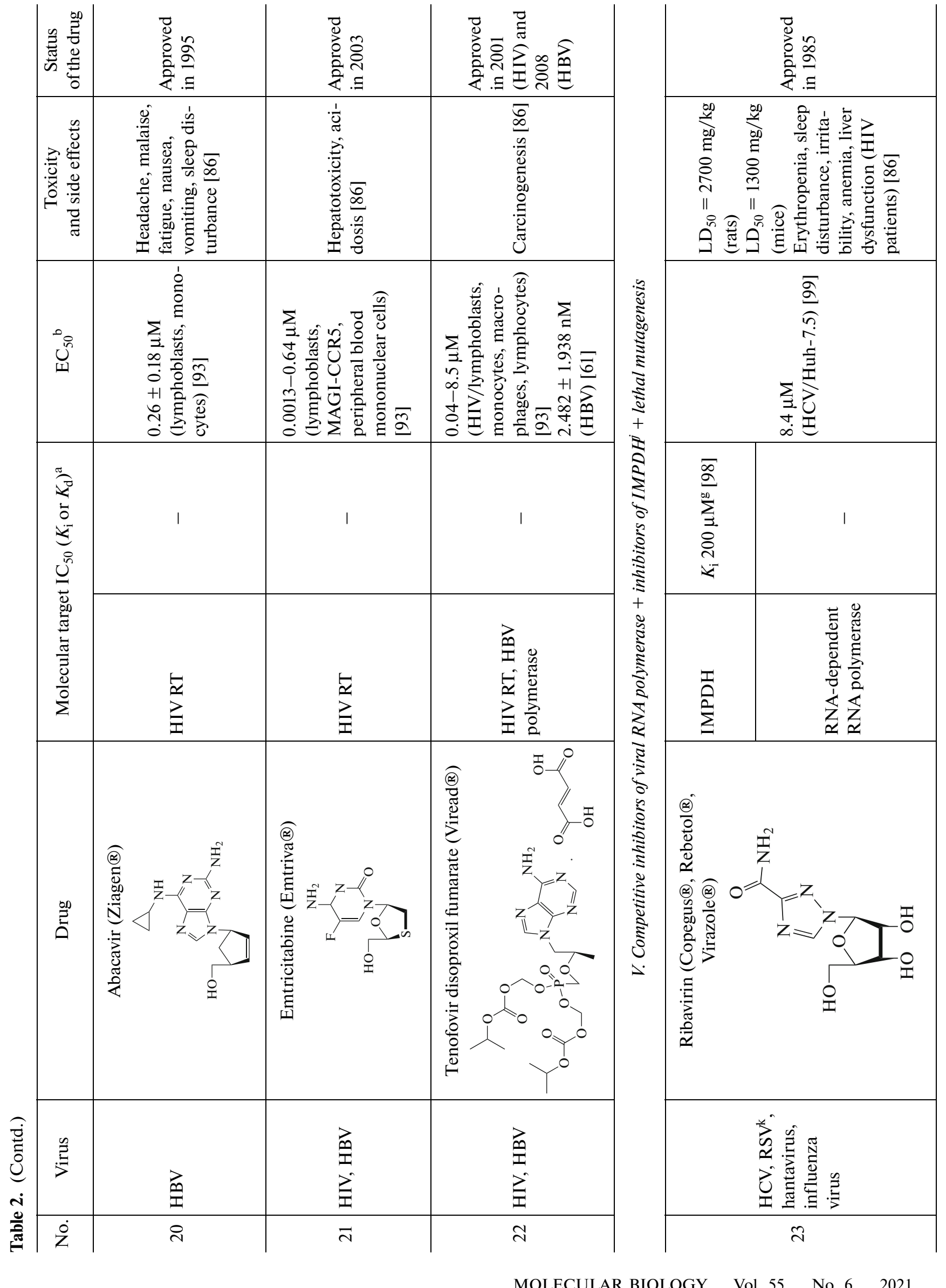




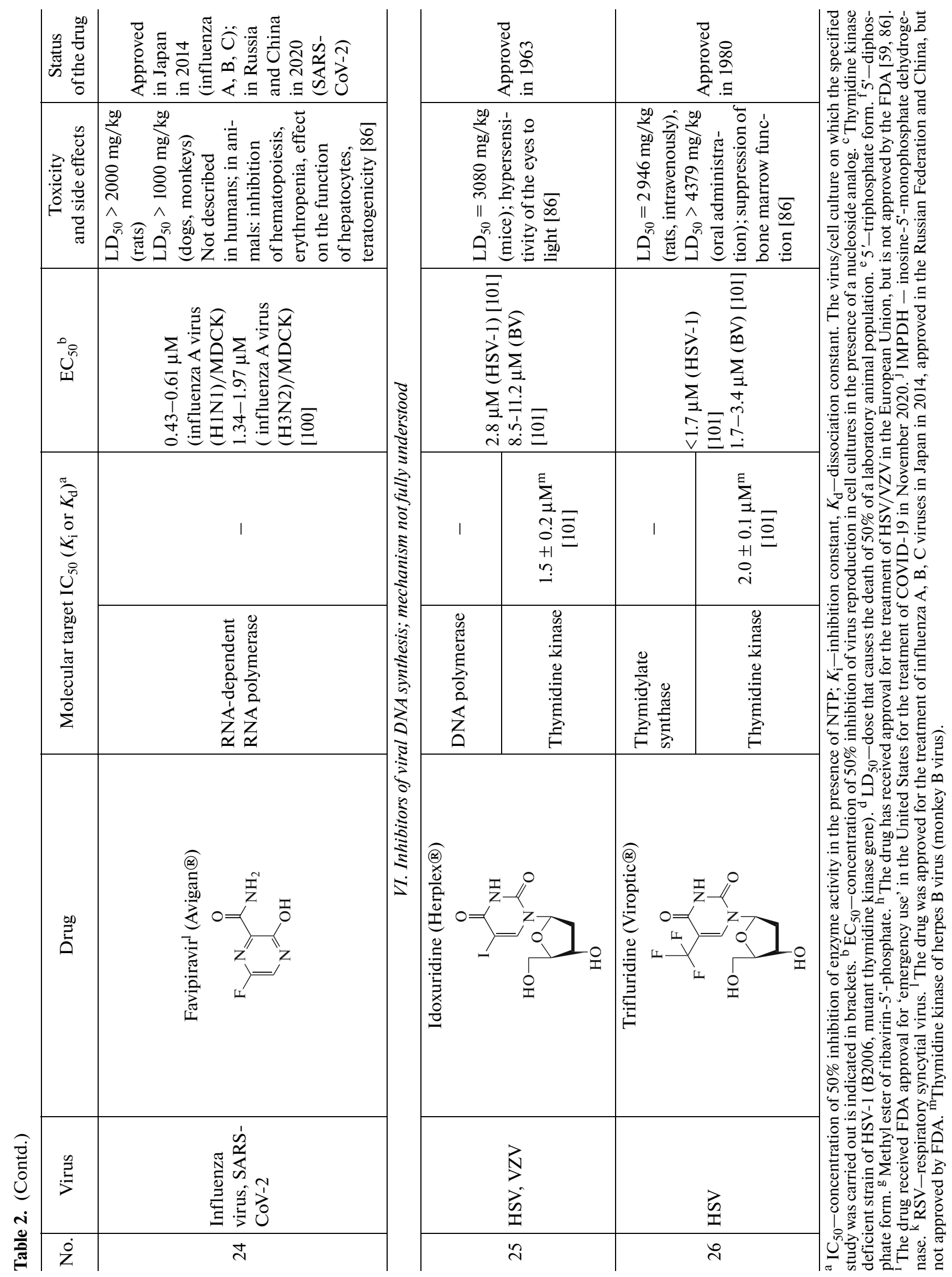


porated, they terminate chain growth due to the absence of a 3'-OH group [59].

Recently, it was reported that RT of retroviruses and hepadnaviruses have a similar structure nucleotide-binding pocket [60]. This is why nucleoside analogs that inhibit HIV reproduction, such as lamivudine and emtricitabine, are also effective for treating patients with hepatitis B.

The mechanism of action of other nucleoside drugs (telbivudine and entecavir; Table 2) against HBV is also via the triphosphorylation cascade of the parent nucleosides, which is followed by inhibition of HBV polymerase. Although telbivudine contains a $3^{\prime}-\mathrm{OH}$ group, which provides the elongation of the viral DNA chain, an alternative mechanism of action may be to terminate the growth of the DNA chain [2]. Entecavir5 '-triphosphate inhibits reverse transcription by HBV polymerase in three ways: (1) it prevents the formation of a covalent complex of HBV polymerase with the growing viral DNA (-) chain (inhibition of the priming activity of HBV polymerase); (2) it kinetically terminates the synthesis of the viral DNA (-) chain, integrating into it instead of dGTP; (3) it kinetically terminates the synthesis of the viral DNA $(+)$ chain on the template $(-)$ chain, inserting instead of dGTP. Molecular modeling and study of the enzymatic activity suggest that the unique property of entecavir to inhibit three types of HBV polymerase activity at once is associated with the optimal correspondence to the spatial arrangement of side groups of amino acid residues in the tail of the NTP binding site while maintaining all key interactions characteristic of the natural substrate, dGTP [61, 62]. Entecavir-5'-triphosphate inhibits DNA polymerase of HBV $\left(K_{\mathrm{i}} 0.0012 \mathrm{mM}\right)$, being a weak inhibitor of cellular DNA polymerases $\alpha$, $\beta, \delta\left(K_{\mathrm{i}} 18-40 \mathrm{mM}\right)$ and mitochondrial DNA polymerase $\left(K_{\mathrm{i}}>160 \mathrm{mM}\right)$ [63], while telbivudine-5'-triphosphate almost does not inhibit polymerase of human cells [64]. Unlike other inhibitors of HBV polymerase (lamivudine, adefovir dipivoxil), entecavir contains a 3'-OH group, which provides the inclusion of several more nucleotides into the viral DNA strand synthesized by the polymerase (kinetic termination).

Sofosbuvir is an inhibitor of the RNA-dependent RNA polymerase (NS5B) of the hepatitis C virus (HCV). Sofosbuvir undergoes rapid intracellular metabolism in the liver with the formation of an active analogue of UTP, which binds to the active site of NS5B and then acts through a chain termination mechanism of the synthesized viral RNA [65-69]. The amino acid sequence of the active site of NS5B RNA polymerase is highly conserved, which ensures high selectivity and low toxicity of sofosbuvir according preclinical and clinical studies [67].

In addition to the HBV polymerase inhibitor, entecavir, kinetic terminators of viral nucleic acid synthesis also include the HSV polymerase inhibitor, brivudine, and the drug remdesivir which is active against a num- ber of RNA viruses: Ebola, Middle East respiratory syndrome coronavirus (MERS-CoV), and severe coronavirus respiratory syndrome (SARS-CoV-1 and SARS-CoV-2) (Table 2) [70-74].

Another drug, ribavirin (Table 2), inhibits certain stages of de novo nucleotide biosynthesis, which reduces the rate of viral replication in the cell. Historically, it was believed that the main mechanism of action of ribavirin against a number of RNA viruses (HCV, Respiratory Syncytial Virus (RSV)) is the inhibition of inosine-5'-monophosphate dehydrogenase and the associated decrease in the level of GTP [75] which is required for translation, transcription and replication of the genome of RNA-viruses. However, competitive inhibition of RNA polymerase, as well as lethal mutagenesis [76], in which no instant inhibition occurs, and viral genomes containing erroneous nucleotides are generated, may be important alternative mechanisms of the antiviral activity of ribavirin 5'-triphosphate. Ribavirin-5'-triphosphate is incorporated into RNA instead of ATP and GTP and forms complementary pairs with uridine and cytidine, which sharply increases the frequency of mutations leading to the emergence of non-viable populations of RNA viruses [77-79].

The drug favipiravir (Table 2), originally approved in Japan in 2014 for the treatment of influenza, has been shown to be effective against SARS-CoV-2 [80]. There are several opinions about the mechanism of action of this compound. Some researchers believe that human hypoxanthine guanine phosphoribosyltransferase plays a key role in the activation of favipiravir as an analogue of the nitrogenous base, converting favipiravir into a 5'-phosphoribosylated metabolite, which is phosphorylated by kinases to active 5'-triphosphate and then inhibits viral RNA polymerase, competing with its native substrates GTP and ATP $[81,82]$. Other studies have shown that favipiravir can act via lethal mutagenesis [83, 84]. Favipiravir, like ribavirin, carries a carboxamide group attached to the triazole residue that freely rotates around the $\mathrm{C}-\mathrm{C}$ bond, so it can mimic both guanine and adenine. Accordingly, the concept of lethal mutagenesis, first described for ribavirin [79], may be valid for favipiravir as well.

Thus, nucleoside analogs represent a class of antiviral agents with a broad spectrum of biological activity. Their effectiveness has already been proven against a number of RNA viruses, including the HIV retrovirus, and picorno-, toga-, rhabdo-, pox- and herpes viruses.

\section{Prodrug Forms of 5'-Nucleoside Phosphates}

The specificity of kinases that catalyze the successive stages of 5'-phosphorylation of nucleosides in the cell limits the possibilities of using nucleosides for the treatment of infectious diseases. The use of 5'-phos- 


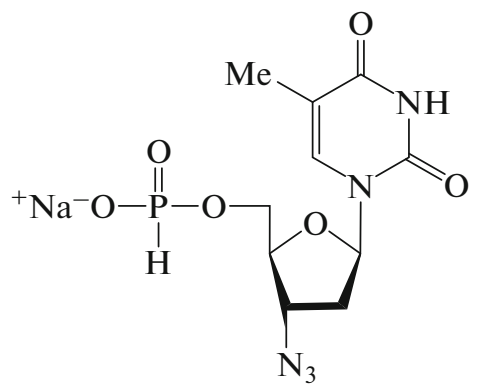

Phosphazide<smiles>Nc1ccn(C[C@H](CO)OCP(=O)(O)O)c(=O)n1</smiles>

Cidofovir<smiles>Nc1ncnc2c1ncn2C[C@H](CO)OCP(=O)(O)O</smiles>

$(S)$-HPMPA

Fig. 4. Phosphonate prodrug forms of nucleotide analogs. (S)-HPMPA, $(S)$-9-(3-hydroxy-2-phosphonylmethoxypropyl)adenine.

phorylated forms of modified nucleosides as medical preparations allows first rate-limiting step of nucleoside phosphorylation to be avoided and increases the efficiency of their action on cells infected with the virus $[102,103]$. This strategy has a number of disadvantages, since the introduction of a polar phosphate group into the modified nucleosides significantly complicates the penetration of such compounds into the cell, and inside it they are exposed to the action of host phosphatases. In this regard, the use of 5'-phosphonate derivatives, which are not subject to dephosphorylation, instead of 5'-phosphate forms of nucleosides, increases the stability of the target compound and improves its penetration through the cell membrane. Based on phosphonate derivatives of nucleosides and their acyclic analogs, a number of drugs have been developed that can convert into triphosphorylated forms and suppress viral replication in the cell (Fig. 4, Table 2) [102, 104].

Phosphazide is a nucleoside reverse transcriptase inhibitor (NRTI) used in antiretroviral therapy for HIV [104]. A domestic drug based on it, Nikavir, has established itself as an effective non-toxic drug for antiretroviral therapy. Acyclic analogs of phosphazide, adefovir and tenofovir, used in antiretroviral therapy, suppress the reproduction of HIV and HBV [102]. Tenofovir disoproxil fumarate, marketed in 2001, has been shown to be more effective than tenofovir due to the presence of two biodegradable hydrophobic residues that improve cell penetration. Cidofovir ( $S$-HPMPC) is a cytidine derivative modified at the ribofuranose fragment with preservation of 2'- and 5'-hydroxyl groups, active against most DNA viruses, including polyomaviruses, papillomaviruses, orthopoxviruses, HCV, VZV, Epstein-Barr virus, adenoviruses and CMV [102].

An alternative to the phosphonate method is the ProTide technology (PROdrug + nucleoTide), which was proposed in the early 1990s [105, 106]. This approach is based on the chemical modification of nucleoside 5'-phosphates by introducing two lipophilic biodegradable residues into the phosphate group (Fig. 5). The resulting derivatives easily penetrate the cell membrane, effectively accumulate in the cell, and are gradually metabolized to biologically active nucleoside-5'-phosphates. The advantages of the ProTide technology in comparison to the phosphonate method include a decrease in the toxicity of modified nucleosides. The first experiments on the application of ProTide technology in antiviral therapy were associated with the use of aryl phosphate and phosphoramidate derivatives of zidovudine [106]. Using T lymphocytes (JM cell line), it was shown that zidovudine 5'-diaryl phosphate at a concentration of about $10 \mu \mathrm{M}$ inhibited HIV-1 replication, while the original zidovudine was almost inactive in this cell line. Substitution of one aryl group for an alanine residue resulted in a significant increase in the inhibitory activity of zidovudine 5'-alanyl(aryl)phosphoramidate $\left(\mathrm{EC}_{50} 0.8 \mu \mathrm{M}\right)$ compared to 5'-diaryl phosphate $\left(\mathrm{EC}_{50}\right.$ $10 \mu \mathrm{M})$. The introduction of amino acid residues containing a hydrophobic side chain seems promising in view of their increased ability to penetrate into the cell and the possibility of hydrolytic cleavage by enzymes inside the cell.

The modified phosphonate nucleoside prodrug tenofovir alafenamide has a higher activity against $\mathrm{HIV}$ and $\mathrm{HCV}$ and is better distributed in tissues than tenofovir. In a range of purine and pyrimidine $2 '-C$ methyl-nucleosides, such derivatives as 7-deaza-2'- $C$ methyladenosine, 2'-methyl-2'-fluorocytidine, and 2'-methyl-2'-fluorouridine have been synthesized, which suppress the replication of a number of RNA and DNA viruses [103]. Modifications of the 5'-phosphate unit lead to an increase in the antiviral activity of 2'- $C$-methyl-nucleosides in the cell. The compound IDX-184, containing an $S$-pivaloyl-2-thioethyl fragment and an $N$-benzylphosphamide group, turned out to be a potent inhibitor of $\mathrm{HCV}$ replication $\left(\mathrm{EC}_{50}\right.$ 0.03-0.2 $\mu \mathrm{M})$. The IDX184 analogue, INX189, exhibited high antiviral activity against $\mathrm{HCV}\left(\mathrm{EC}_{50} 0.01 \mu \mathrm{M}\right)$. The presence of a modified phosphate residue contributes to the greater efficiency of INX189 due to the creation of a higher concentration of NTP in cells compared to the initial 2'-C-methylguanosine (the intracellular concentration of NTP from INX189 is 4 times higher than the concentration of NTP from 
<smiles></smiles>

Diaryl phosphate AZT

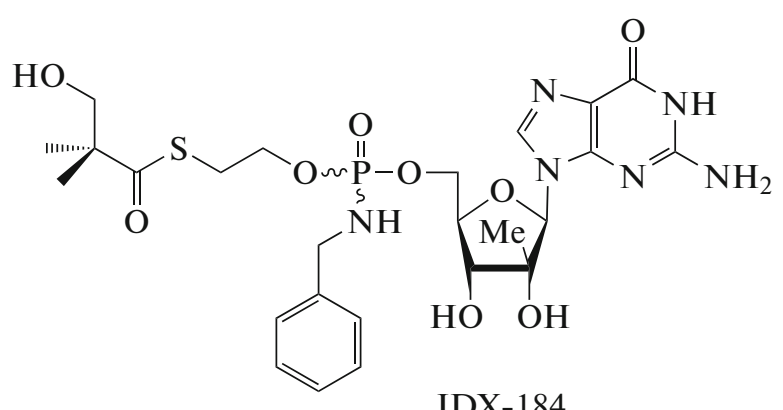
IDX-184<smiles>COC(=O)[C@H](C)NP(=O)(OCC1C[C@@H]2N[C@@H](CC2N)O1)Oc1ccccc1</smiles>

Alafenamide AZT<smiles>CC(C)OC(=O)[C@H](C)NP(=O)(CO[C@@H](C)Cn1cnc2c(N)ncnc21)Oc1ccccc1</smiles><smiles>COc1nc(N)nc2c1ncn2C12CC(COP(=O)(N[C@@H](C)C(=O)OCC(C)(C)C)Oc3cccc4ccccc34)(OC1O)C(O)(O)C2(C)O</smiles>

BMS-986094

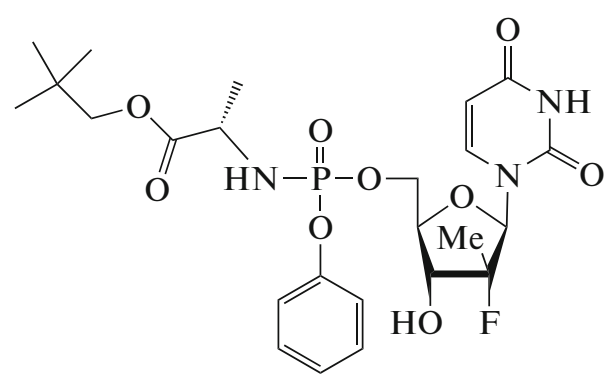

Sofosbuvir<smiles>CCC(CC)OC(=O)[C@H](C)NP(=O)(OCC1O[C@@](C#N)(c2ccc3c(N)ncnn23)[C@H](O)C1O)Oc1ccccc1</smiles>

Remdesivir

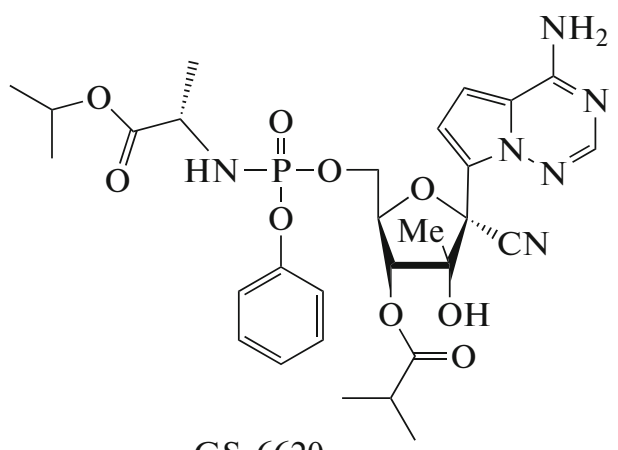

GS-6620

Fig. 5. Prodrug forms of nucleoside phosphate analogs obtained using the ProTide technology. AZT, azidothymidine. 
2 '- $C$-methylguanosine $24 \mathrm{~h}$ after cell culture treatment). The use of another 2'- $C$-methylguanosine derivative, BMS-986094 (INX-189), in combination with ribavirin produced a significant synergistic effect in inhibiting Dengue virus replication in vitro $\left(\mathrm{EC}_{90}\right.$ $0.11 \mu \mathrm{M}$ for INX-189, $\mathrm{EC}_{90} 100 \mu \mathrm{M}$ for ribavirin; for combination of two drugs: $\mathrm{EC}_{90} 0.022 \mu \mathrm{M}$ for INX-189 and $\mathrm{EC}_{90} 10 \mu \mathrm{M}$ for ribavirin) [107].

During study of the structure-activity dependence of modified derivatives of pyrimidine nucleosides, it was shown that the ProTide derivative of 2'-methyl-2'fluorouridine (Fig. 5) effectively inhibited HSV replication, while the initial nucleoside, 2'-methyl-2'-fluorouridine, showed very weak antiviral activity. The $S \mathrm{p}$-isomer (the position of substituents at the phosphorus atom corresponds to the $S$-configuration) of this ProTide derivative (the drug sofosbuvir) is much more active $\left(\mathrm{EC}_{90} 0.42 \mu \mathrm{M}\right)$ than the $R \mathrm{p}$-isomer (the position of the substituents at the phosphorus atom corresponds to the $R$-configuration, $\mathrm{EC}_{90} 7.5 \mu \mathrm{M}$ ) and is used for the treatment of hepatitis $\mathrm{C}$ in combination with other drugs (Fig. 5).

Remdesivir, an analogue of adenosine-5'-monophosphate, is considered as a promising prodrug that can inhibit RNA-dependent RNA polymerase of coronaviruses. This drug was originally developed for the treatment of Ebola and Marburg hemorrhagic fever, and its antiviral activity against SARS-CoV $\left(\mathrm{EC}_{50} 0.069 \mu \mathrm{M}\right)$ and MERS-CoV $\left(\mathrm{EC}_{50} 0.032 \mu \mathrm{M}\right)$ was discovered. Remdesivir is metabolized to the triphosphate form much faster than its analogue, 1-cyano4-aza-7,9-dideazaadenosine, which has significantly lower antiviral activity against SARS-CoV and MERS-CoV viruses. According to the recent studies, remdesivir effectively inhibits SARS-CoV-2 in Vero E6 cell culture $\left(\mathrm{EC}_{50} 0.77 \mu \mathrm{M}\right)$, while exhibiting low cytotoxicity $\left(50 \%\right.$ concentration of cell death $\left(\mathrm{CC}_{50}>100 \mu \mathrm{M}\right)$ and a high selectivity index (SI $>129.87$ ) [80].

By modifying the structure of remdesivir by introducing a 2 '- $C$-methyl group and a 3 '- $O$-isobutyroyl group, a new prodrug nucleoside analogue (GS-6620, $\mathrm{Sp}$-isomer) was obtained, which effectively accumulates in hepatocytes and suppresses the reproduction of $\mathrm{HCV}$ replicons at low concentrations $\left(\mathrm{EC}_{50}\right.$ in range 68-427 nM) [108, 109].

In the cell, the phosphamide residue of the ProTide drug undergoes enzymatic cleavage in the presence of esterase (CES1) and cathepsin A (CTSA) to form the corresponding nucleoside 5 -monophosphates. That is why ProTide drugs are effective against viruses that infect cells with CES1 and CTSA expression (for example, HCV in hepatocytes) [110].

In some cases, the monophosphorylation step does not limit the overall rate of the triphosphorylation reaction, which may be due to the structural peculiarities of the nucleoside derivative. For example, for azidothymidine, the rate-limiting step is the formation of the 5'-diphosphate form under the action of thymidylate kinase. Nucleoside diphosphate kinase works with low efficiency on non-optimal substrates: uridine-5'-diphosphate and 2',3'-didehydro-2',3'-dideoxyuridine-5'-diphosphate [111].

In connection with the above factors, the development of prodrug tri- and diphosphate forms of nucleosides is considered as a more universal approach that allows them to bypass potential rate-limiting steps and side metabolic processes occurring mainly at the level of nucleosides and their 5'-monophosphates (for example, deamination), and ultimately efficiently deliver biologically active NDP and NTP into the cell. In view of the low stability and high polarity of NDP and NTP, the main difficulties in the development of such drug forms are associated with the low stability of the pyrophosphate bond and the delivery of such compounds into the cell.

A new synthetic approach developed in the laboratory of prof. Chris Meier, suggests: (1) the use of partially charged forms of NDP and NTP, which are resistant to hydrolysis; (2) the introduction of biodegradable lipophilic residues at the terminal phosphate group. In this manner a number of biologically active transport forms of AZT and stavudine have already been obtained (Fig. 6) and their antiviral activity has been studied [111]. Chemical hydrolysis of the prodrug form of AZT in the form of $\delta$-cycloSaligenyl diphosphate (Fig. 6a) leads to the formation of a mixture of 5'-mono- and 5'-diphosphate forms of AZT with a predominance of the monophosphate form in the mixture. Taking this into account, bis(acyloxybenzyl)nucleoside di- and triphosphates, DiP- and TriPprodrugs, were proposed as more promising prodrug forms (Fig. 6b). Treatment of DiP- and TriP-derivatives of stavudine (d4T) with cell extracts, blood serum or carboxyesterase from pig liver led to the formation of predominantly corresponding di- and triphosphates; at the same time, asymmetric prodrug forms $\left(R_{1} \neq R_{2}, R_{1}-M e\right.$ or $\left.B u, R_{2}>C_{4} H_{9}\right)$ were more resistant to enzymatic hydrolysis of the pyrophosphate group compared to symmetric ones $\left(\mathrm{R}_{1}=\mathrm{R}_{2}\right)$.

In experiments on $\mathrm{T}$ cells, $\mathrm{DiP}$ and TriP derivatives of stavudine (Fig. 6b) inhibited HIV RT more effectively than the non-phosphorylated drug (d4T). Prodrugs of nucleosides containing acyl residues with $\mathrm{R}_{1,2}=\mathrm{C}_{8} \mathrm{H}_{17}$ exhibited high anti-HIV activity in experiments on CEM cell culture, which proves their ability to penetrate cell membranes with subsequent release of phosphorylated d4T metabolites.

Thus, phosphate prodrug forms based on modified nucleosides are already a well-proven approach in the development of new antiviral agents. The introduction of hydrophobic residues in the 5'-phosphate group of the modified nucleoside (ProTide technology) makes it possible to increase the efficiency of its action as an inhibitor of viral replication. ProTide technology with the use of phosphamide derivatives of nucleosides is 


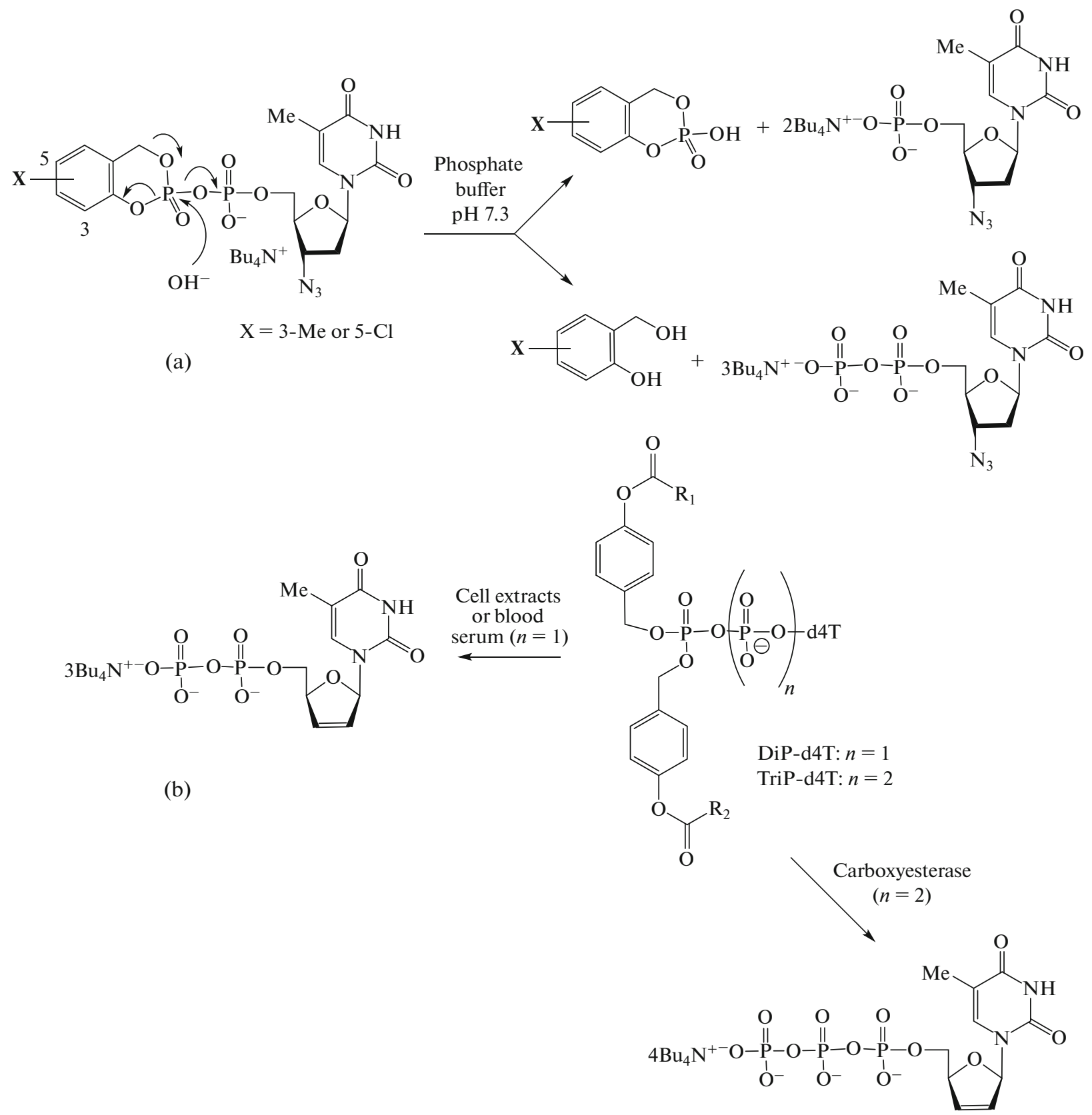

Fig. 6. Hydrolysis of diphosphate and triphosphate prodrugs of AZT (a) and stavudine d4T (b) (compiled from the data of [111]).

another modern approach for the creation of effective drugs for the treatment of viral and oncological diseases. The ProTide technology has served as the basis for the creation of 3 effective antiviral drugs: sofosbuvir for the treatment of hepatitis $\mathrm{C}$, alafenamide tenofovir for the antiretroviral therapy of HIV and hepatitis C, and remdesivir for the treatment of COVID-19.

Nucleoside analogs containing nicotinic acid residues are considered as an alternative to the prodrug forms discussed above [112]. The introduction of nicotinic acid residues into the carbohydrate unit of the nucleoside makes it possible to reduce the toxicity of the drug, increase its stability in the cell, prolong its life time in the bloodstream, and also provide permeability through the blood-brain barrier [113, 114].

\section{HYDROPHOBIC COMPOUNDS WITH ANTI-VIRAL PROPERTIES \\ Non-Nucleoside Hydrophobic Compounds with Antiviral Properties}

The mechanism of biological activity of a number of antiviral drugs with pronounced hydrophobic properties is based on the ability to block the work of viral enzymes by binding to a certain part of the enzyme. Unlike drugs created on nucleosides, the targets of 


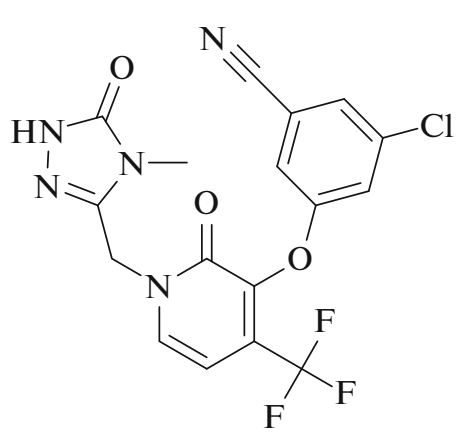

Fig. 7. The structure of Doravirine.

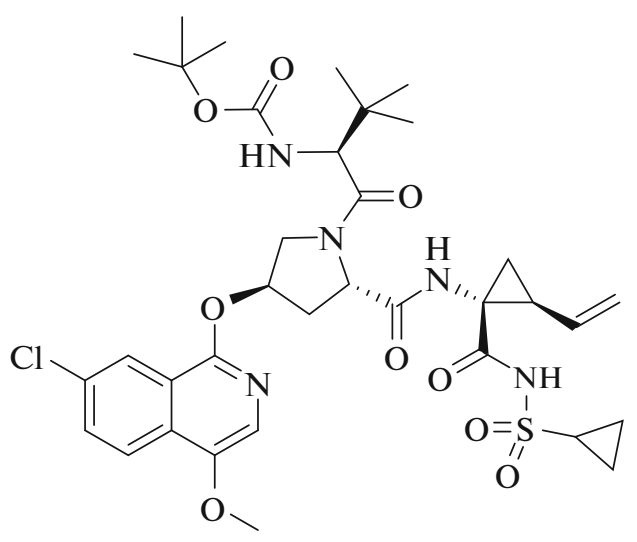

Fig. 8. The structure of Beclabuvir.

which are the nucleoside-binding active site of polymerases, these compounds do not undergo chemical transformations inside the cell. Their targets are the hydrophobic regions of viral enzymes.

The structure of HIV-1 RT contains a hydrophobic region, the so-called hydrophobic pocket, which is located at a distance of about $15 \AA$ from the nucleotide-binding site [115]. When a hydrophobic compound enters this pocket and a strong bond is formed with it, the enzyme loses its conformational mobility, which leads to allosteric inhibition of its activity [116]. Inhibitors of a hydrophobic nature that are able to bind in the hydrophobic pocket of HIV-1 RT are nonnucleoside inhibitors (HIV-1 NNRTI). They are specific for the structure of the hydrophobic pocket of HIV-1 RT and have no activity against HIV-2 RT and other retroviruses. In clinical practice, these inhibitors are used in complex therapy of HIV-1 infection [45]. FDA-approved first-generation HIV-1 NNRTIs include nevirapine, delavirdine, and efavirenz; secondgeneration drugs include etravirine and rilpivirine. The class of diarylpyrimidines, the second generation drugs, turned out to be promising for the creation of inhibitors of this kind due to their conformational flexibility, as a result of which they can rearrange and adapt to various amino acid substitutions within the hydrophobic pocket. In 2018, the FDA approved another drug of this class, doravirine (Fig. 7).

New variants of inhibitors of the diarylpyrimidine class are currently being actively investigated as potential antiviral agents [117-121]. Thus, HCV is an enveloped RNA virus that belongs to the Flaviviridae family. The structure of the RNA-dependent RNA polymerase of this virus, NS5B, contains a hydrophobic pocket located at a distance of $30 \AA$ from the nucleotide-binding active site [122]. A large number of hydrophobic aromatic compounds capable of binding to this NS5B site have been investigated [123-129]. Currently, dasabuvir, an allosteric inhibitor of the enzymatic activity of NS5B from HCV genotypes 1a and $1 \mathrm{~b}\left(\mathrm{IC}_{50} 2.8\right.$ and $10.7 \mathrm{nM}$, respectively), is used in the treatment of HCV. This drug has received FDA approval and is listed on the Essential Drugs List. Another drug of the piperazinecarboxamide class is beclabuvir (Fig. 8); it also acts as an allosteric inhibitor of RNA polymerase of HCV. The efficacy and safety of its use was studied in the following complexes: beclabuvir + pegylated interferon + ribavirin [130] and beclabuvir + asunaprevir (NS3 serine protease inhibitor) + daclatasvir (NS5A protein inhibitor) [131]. Based on clinical evaluation of the efficacy, safety and pharmacokinetic properties of these complexes, the Pharmaceutical and Food Safety Bureau of Japan (PFSB) approved the use of Ximency. This drug is the second of the above complexes: beclabuvir + asunaprevir + daclatasvir, with fixed doses of all components, for the treatment of patients infected with HCV genotype 1 [132].

\section{Effect of Hydrophobic Substituents on the Antiviral Activity of Nucleoside Derivatives}

Derivatives of pyrimidines, such as $2^{\prime}, 5^{\prime}$-bis-O(tert-butyldimethylsilyl)-pentafuranosyl-3'-spiro-5"-(4"amino-1",2"-oxathiolane-2",2"-dioxide)pyrimidine (TSAO), are able to bind to HIV-1 RT in vitro and inhibit the activity of the enzyme by the allosteric mechanism [133-136]. However, when comparing the efficiency of inhibition of HIV RT by these nucleoside derivatives with the efficiency of NNRTI HIV, these derivatives of pyrimidines are significantly inferior. Their inhibitory effect is lost even with minor amino acid substitutions in the structure of HIV-1 RT, which do not affect the inhibitory properties of known HIV NNRTIs [137]. In addition, these nucleoside analogs are highly toxic, and attempts to reduce toxicity by varying the structure of substituents led to a decrease in their inhibitory activity [138].

Studies of the antiviral activity of various nucleoside derivatives were performed in cellular systems against a large group of flaviviruses, which are carried by arthropods (arboviruses) and belong to the causative agents of socially significant endemic diseases [139-144]. Among them are tick-borne encephalitis virus, Dengue virus, yellow fever virus, Japanese encephalitis virus, and 
West Nile virus. It turned out that the highest antiviral activity in vitro is exhibited by nucleosides containing triphenylmethyl substituents at different positions of the pentafuranose ring. The mechanism of their action cannot yet be considered definitively established, although Eyer L. et al. [145], based on data on the inhibition of the Dengue virus in cellular systems, suggested that these nucleoside derivatives inhibit the process of viral RNA replication by interacting with the active center of RNA-dependent RNA polymerase.

In cases where bulky hydrophobic substituents are found in the nucleoside analog with aglycone, the antiviral effect is determined by the amphipathic nature of these compounds. They inhibit the initial stage of fusion of the outer membrane of enveloped viruses with the membranes of the infected cells. The antiviral efficacy of such nucleoside derivatives was demonstrated by the example of HSV-1 and HSV-2 $\left(\mathrm{IC}_{50} 48 \mathrm{nM}\right)$ [146], as well as tick-borne encephalitis virus $\left(\mathrm{IC}_{50} 18-24 \mathrm{nM}\right)$ [147]. In concentrations sufficient to create an antiviral effect, these nucleosides have neither a cytotoxic nor cytostatic effect on cells.

\section{CONCLUSION}

This review considers the structural and functional characteristics of known nucleoside analogues, which determine their antiviral or antiparasitic properties. Knowledge of the characteristics of cellular metabolism of natural nucleosides is necessary to identify those stages of metabolic processes that may be sensitive to drugs based on nucleosides. Nucleoside phosphorylases can be targets for antiparasitic agents, in cases where these enzymes are noticeably different in humans and the parasite. The antiviral effect of nucleoside analogs is mainly associated with their ability to undergo enzymatic phosphorylation inside the cell with the formation of modified nucleoside-5'-mono-, di- and triphosphates. These metabolites then compete with natural NTPs for binding to the active site of viral polymerases and either remain competitive inhibitors, or become terminators of viral DNA/RNA chain growth or triggers of viral genome mutagenesis. Nucleoside analogs bearing hydrophobic substituents can be both inhibitors of viral enzymes involved in the replication of viral nucleic acids and inhibitors of the process of viral penetration into the cell, and can also act on cellular enzymes indirectly involved in viral replication (ribavirin). The specific mechanism of antiviral action depends on the structure and position of the substituent in the nucleoside.

Specific inhibition of viral enzymes by nucleoside and non-nucleoside compounds containing a hydrophobic link can also occur by the allosteric mechanism if hydrophobic regions are present in the enzyme structure at a relatively short distance from the active site. Enzymes with such a structure include HIV-1 RT and RNA-dependent RNA-polymerase of a number of viruses, which makes them promising targets in the search for new antiviral agents.

Almost all drugs, in addition to the desired effect, cause side effects associated with the toxic effect of the drug on healthy cells, and the toxic effect on the systems of inactivation and excretion of the drug by the liver and kidneys. Nucleoside-based drugs can be toxic as a result of inhibiting enzymes that metabolize natural nucleosides. Another serious problem limiting the use of nucleoside drugs is the development of drug resistance in an infectious agent. This is usually a consequence of long-term use of the drug in the treatment of latent and chronic infections. Resistance occurs when mutations leading to the formation of drugresistant strains accumulate in the pathogen's genome [148]. To increase the effectiveness and reduce the dosage of the drug, the selectivity of its action on targets in the body is important.

Currently, when creating drugs based on nucleosides, one should adhere to a strategy that decreases the toxicity to human and increases their effectiveness of action on infected cells. This strategy is based on the use of prodrugs of modified nucleosides. The combination of hydrophobic residues at the 5'-phosphate group of the modified nucleoside (ProTide technology) enhances its effect on cells infected with the virus. The ProTide technology with the use of phosphoramidate nucleoside derivatives is a highly effective approach to the development of new drugs for the treatment of viral diseases. Using this technology, three effective antiviral drugs have been obtained: sofosbuvir for the treatment of hepatitis $\mathrm{C}$, tenofovir alafenamide for antiretroviral therapy of HIV and hepatitis C, and remdesivir for the treatment of COVID-19. Currently, approaches are being developed related to the use of di- and triphosphate forms of nucleoside prodrugs capable of exerting a selective effect due to their accumulation in cells.

\section{ACKNOWLEDGMENTS}

The authors are grateful to $\mathrm{PhD}$ (Chem.) V.O. Zenchenko for help in the preparation of graphic materials, $\mathrm{PhD}$ (Chem.) V.E. Oslovsky and $\mathrm{PhD}$ (Chem.) D.I. Osolodkin for valuable comments and recommendations during the preparation of the review.

\section{FUNDING}

The study was financially supported by the Russian Foundation for Basic Research, project nos. 18-29-09037 and 20-34-70116.

\section{COMPLIANCE WITH ETHICAL STANDARDS}

In carrying out this work, all ethical standards were observed.

MOLECULAR BIOLOGY Vol. 55 No. 62021 
Conflict of interest. The authors declare that they have no conflicts of interest.

This article does not contain any studies involving humans and animals as objects.

\section{REFERENCES}

1. De Clercq E., Field H.J. 2006. Antiviral prodrugs: The development of successful prodrug strategies for antiviral chemotherapy. Br. J. Pharmacol. 147 (1), 1-11.

2. De Clercq E., Neyts J. 2009. Antiviral agents acting as DNA or RNA chain terminators. In: Antiviral Strategies. Eds. Krausslich H.G., Bartenschlager R. Berlin, Springer, pp. 53-84.

3. Jordheim L.P., Durantel D., Zoulim F., Dumontet C. 2013. Advances in the development of nucleoside and nucleotide analogues for cancer and viral diseases. Nat. Rev. Drug Discov. 12 (6), 447-464.

4. Jordan P.C., Stevens S.K., Deval J. 2018. Nucleosides for the treatment of respiratory RNA virus infections. Antivir. Chem. Chemother. 26, 2040206618764483.

5. De Clercq E. 2019. New nucleoside analogues for the treatment of hemorrhagic fever virus infections. Chem. Asian J. 14 (22), 3962-3968.

6. Postigo M.P., Guido R.V., Oliva G., Castilho M.S., da R. Pitta I., de Albuquerque J.F., Andricopulo A.D. 2010. Discovery of new inhibitors of Schistosoma mansoni PNP by pharmacophore-based virtual screening. J. Chem. Inf. Model. 50 (9), 1693-1705.

7. Tavares N.C., de Aguiar P.H.N., Gava S.G., Oliveira G., Mourão M.M. 2016. Schistosomiasis: Setting routes for drug discovery. In: Special Topics in Drug Discovery. Eds. Chen T., Chai S.C. London: InTechOpen, pp. 105-132.

8. El Kouni M.H. 2017. Pyrimidine metabolism in schistosomes: A comparison with other parasites and the search for potential chemotherapeutic targets. Comp. Biochem. Physiol. B: Biochem. Mol. Biol. 213, 55-80.

9. Evans G.B., Tyler P.C., Schramm V.L. 2018. Immucillins in infectious diseases. ACS Inf. Dis. 4 (2), 107-117.

10. Drenichev M.S., Oslovsky V.E., Mikhailov S.N. 2016. Cytokinin nucleosides - natural compounds with a unique spectrum of biological activities. Curr. Top. Med. Chem. 16 (23), 2562-2576.

11. Oslovsky V.E., Drenichev M.S., Sun L., Kurochkin N.N., Kunetsky V.E., Mirabelli C., Neyts J., Leyssen P., Mikhailov S.N. 2017. Fluorination of naturally occurring $N^{6}$-benzyladenosine remarkably increased its antiviral activity and selectivity. Molecules. 22 (7), 1219.

12. Traut T.W. 1994. Physiological concentrations of purines and pyrimidines. Mol. Cell. Biochem. 140 (1), 1-22.

13. Jensen K.F., Dandanell G., Hove-Jensen B., Willemoës M. 2008. Nucleotides, nucleosides, and nucleobases. EcoSal Plus. 3 (1), 1-39.

14. Mathews C.K., van Holde K.E. 1996. Biochemistry, 2nd ed. California: Benjamin Cummings, pp. 784-817.

15. Lewkowicz E.S., Iribarren A.M. 2006. Nucleoside phosphorylases. Curr. Org. Chem. 10 (11), 1197-1215.

16. Alexeev C.S., Kulikova I.V., Gavryushov S., Tararov V.I., Mikhailov S.N. 2018. Quantitative prediction of yield in transglycosylation reaction catalyzed by nucleoside phosphorylases. Adv. Synth. Catal. 360 (16), 30903096.

17. Valentin-Hansen P. 1978. Uridine-cytidine kinase from Escherichia coli. Methods Enzymol. 51, 308-314.

18. Moran L.A., Horton H.R., Scrimgeour K.G., Perry M.D. 2012. Principles of Biochemistry, 5th ed. Ed. Jaworski A. London: Pearson.

19. Brown A.M., Hoopes S.L., White R.H., Sarisky C.A. 2011. Purine biosynthesis in archaea: Variations on a theme. Biol. Direct. 6, 63.

20. Thia-Toong T.L., Roovers M., Durbecq V., Gigot D., Glansdorff N., Charlier D. 2002. Genes of de novo pyrimidine biosynthesis from the hyperthermoacidophilic crenarchaeote Sulfolobus acidocaldarius: Novel organization in a bipolar operon. J. Bacteriol. 184 (16), 4430-4441.

21. He B., Zalkin H. 1992. Repression of Escherichia coli purB is by a transcriptional roadblock mechanism. J. Bacteriol. 174 (22), 7121-7127.

22. Hayes W. 1964. The Genetics of Bacteria and Their Viruses. Studies in Basic Genetics and Molecular Biology, 2nd ed. New York: Wiley.

23. Hyde J.E. 2007. Targeting purine and pyrimidine metabolism in human apicomplexan parasites. Curr. Drug Targets. 8 (1), 31-47.

24. Hazleton K.Z., Ho M.C., Cassera M.B., Clinch K., Crump D.R., Rosario I., Jr., Schramm V.L. 2012. Acyclic immucillin phosphonates: Second-generation inhibitors of Plasmodium falciparum hypoxanthine-guanine-xanthine phosphoribosyltransferase. Chem. Biol. 19 (6), 721-730.

25. Senft A.W., Crabtree G.W. 1983. Purine metabolism in the schistosomes: Potential targets for chemotherapy. Pharmacol. Ther. 20 (3), 341-356.

26. Lago E.M., Xavier R.P., Teixeira T.R., Silva L.M., da Silva Filho A.A., de Moraes J. 2018. Antischistosomal agents: State of art and perspectives. Future Med. Chem. 10 (1), 89-120.

27. Lindmark D.G., Jarroll E.L. 1982. Pyrimidine metabolism in Giardia lamblia trophozoites. Mol. Biochem. Parasitol. 5 (5), 291-296.

28. Aldritt S.M., Tien P., Wang C.C. 1985. Pyrimidine salvage in Giardia lamblia. J. Exp. Med. 161 (3), 437-445.

29. Vitti G.F., O'Sullivan W.J., Gero A.M. 1987. The biosynthesis of uridine 5'-monophosphate in Giardia lamblia. Int. J. Parasitol. 17 (3), 805-812.

30. Kicska G.A., Tyler P.C., Evans G.B., Furneaux R.H., Kim K., Schramm V.L. 2002. Transition state analogue inhibitors of purine nucleoside phosphorylase from Plasmodium falciparum. J. Biol. Chem. 277 (5), 3219-3225.

31. Shi W., Ting L.M., Kicska G.A., Lewandowicz A., Tyler P.C., Evans G.B., Schramm V.L. 2004. Plasmodium falciparum purine nucleoside phosphorylase: Crystal structures, immucillin inhibitors, and dual catalytic function. J. Biol. Chem. 279 (18), 18103-18106.

32. Schramm V.L. 2018. Enzymatic transition states and drug design. Chem. Rev. 118 (22), 11194-11258.

33. Cassera M.B., Hazleton K.Z., Merino E.F., Obaldia III N., Ho M.C., Murkin A.S., DePinto R., Gutierrez J.A., Almo S.C., Evans G.B., Babu Y.S., 
Schramm V.L. 2011. Plasmodium falciparum parasites are killed by a transition state analogue of purine nucleoside phosphorylase in a primate animal model. PLoS One. 6 (11), e26916.

34. Suarez J., Haapalainen A.M., Cahill S.M., Ho M.C., Yan F., Almo S.C., Schramm V.L. 2013. Catalytic site conformations in human PNP by ${ }^{19}$ F-NMR and crystallography. Chem. Biol. 20 (2), 212-222.

35. Kukhanova M.K., Korovina A.N., Kochetkov S.N. 2014. Human herpes sinplex virus: Life cycle and and search for inhibitors. Usp. Biol. Khim. 54, 457-494.

36. Aivazashvili V.A., Mikhailov S.N., Padyukova N.Sh., Karpeisky M.Ya., Bibilashvili R.Sh. 1986. 1-(3'-Cmethyl- $\beta$ - $D$-ribofuranosyl)uracyl-5'-triphosphate A terminator of RNA polymerate-catalyzed RNA synthesis. Bioorg. Khim. 12 (5), 708-710.

37. Tunitskaya V.L., Rusakova E.E., Padyukova N.S., Ermolinskii B.S., Chernyi A.A., Kochetkov S.N., Mikhailov S.N. 1997. Substrate properties of C'-methyl UTP derivatives in T7 RNA polymerase reactions. Evidence for N-type NTP conformation. FEBS Lett. 400 (3), 263-266.

38. Aivazashvili V.A., Mikhailov S.N., Padyukova N.Sh., Bibilashvili R.Sh., Karpeiskii M.Ya. 1987. 5'-C-methylnucleoside triphosphates in the reaction of RNA synthesis catalyzed by Escherichia coli RNA polymerase. Mol. Biol. (Moscow). 21 (4), 1080-1091.

39. Savochkina L.P., Sviryaeva T.V., Beigel'man L.N., Padyukova N.Sh., Kuznetsov D.A., Lysov Yu.P., Mikhailov S.N., Bibilashvili R.Sh. 1989. Substrate properties of C-methylnucleoside triphosphates in the reaction of RNA synthesis catalyzed by Escherichia coli RNA polymerase. Mol. Biol. (Moscow). 23 (6), 17001710.

40. Chen P., Shakhnovich E.I. 2009. Lethal mutagenesis in viruses and bacteria. Genetics. 183 (2), 639-650.

41. Elion G.B., Furman P.A., Fyfe J.A., De Miranda P., Beauchamp L., Schaeffer H.J. 1977. Selectivity of action of an antiherpetic agent, 9-(2-hydroxyethoxymethyl)guanine. Proc. Natl. Acad. Sci. U. S. A. 74 (12), 5716-5720.

42. Hodge R.V. 1993. Famciclovir and penciclovir. The mode of action of famciclovir including its conversion to penciclovir. Antiviral Chem. Chemother. 4 (2), 67-84.

43. Aoki F.Y. 2015. Antivirals against herpes viruses. In Mandell, Douglas, and Bennett's Principles and Practice of Infectious Diseases, 8th ed. Eds. Bennett J.E., Dolin R., Blaser M.J. Philadelphia: Elsevier, pp. 546-562.

44. Matthews T., Boehme R. 1988. Antiviral activity and mechanism of action of ganciclovir. Rev. Infect. Dis. 10 (Suppl. 3), S490-S494.

45. De Clercq E., Li G. 2016. Approved antiviral drugs over the past 50 years. Clin. Microbiol. Rev. 29 (3), 695-747.

46. North T.W., Cohen S.S. 1979. Aranucleosides and aranucleotides in viral chemotherapy. Pharmacol. Ther. 4 (1), 81-108.

47. De Clercq E. 1997. In search of a selective antiviral chemotherapy. Clin. Microbiol. Rev. 10 (4), 674-693.

48. Descamps J., De Clercq E. 1981. Specific phosphorylation of E-5-(2-iodovinyl)-2'-deoxyuridine by herpes simplex virus-infected cells. J. Biol. Chem. 256 (12), 5973-5976.

49. Allaudeen H.S., Kozarich J.W., Bertino J.R., De Clercq E. 1981. On the mechanism of selective inhibition of herpesvirus replication by $(E)-5$-(2-bromovinyl)-2'deoxyuridine. Proc. Natl. Acad. Sci. U. S. A. 78 (5), 2698-2702.

50. De Clercq E. 2004. Discovery and development of BVDU (brivudin. as a therapeutic for the treatment of herpes zoster. Biochem. Pharmacol. 68 (12), 23012315.

51. De Clercq E. 2011. The clinical potential of the acyclic (and cyclic. nucleoside phosphonates. The magic of the phosphonate bond. Biochem. Pharmacol. 82 (2), 99-109.

52. De Clercq E. 2007. Acyclic nucleoside phosphonates: Past, present and future. Bridging chemistry to HIV, HBV, HCV, HPV, adeno-, herpes-, and poxvirus infections: The phosphonate bridge. Biochem. Pharmacol. 73 (7), 911-922.

53. De Clercq E., Holý A. 2005. Acyclic nucleoside phosphonates: A key class of antiviral drugs. Nat. Rev. Drug Discov. 4 (11), 928-940.

54. Balzarini J., Hao Z., Herdewijn P., Johns D.G., De Clercq E. 1991. Intracellular metabolism and mechanism of anti-retrovirus action of 9-(2-phosphonylmethoxyethyl)adenine, a potent anti-human immunodeficiency virus compound. Proc. Natl. Acad. Sci. U. S. A. 88 (4), 1499-1503.

55. Balzarini J., Holy A., Jindrich J., Dvorakova H., Hao Z., Snoeck R., De Clercq E. 1991. 9-[(2RS)-3-fluoro-2phosphonylmethoxypropyl] derivatives of purines: A class of highly selective antiretroviral agents in vitro and in vivo. Proc. Natl. Acad. Sci. U. S. A. 88 (11), 4961-4965.

56. De Clercq E. 1991. Broad-spectrum anti-DNA virus and anti-retrovirus activity of phosphonylmethoxyalkylpurines and -pyrimidines. Biochem. Pharmacol. 42 (5), 963-972.

57. Cherrington J.M., Allen S.J.W., Bischofberger N., Chen M.S. 1995. Kinetic interaction of the diphosphates of 9-(2-phosphonylmethoxyethyl)adenine and other anti-HIV active purine congeners with HIV reverse transcriptase and human DNA polymerases $\alpha, \beta$ and $\gamma$. Antivir. Chem. Chemother. 6 (4), 217-221.

58. Kramata P., Votruba I., Otová B., Holý A. 1996. Different inhibitory potencies of acyclic phosphonomethoxyalkyl nucleotide analogs toward DNA polymerases alpha, delta and epsilon. Mol. Pharmacol. 49 (6), 1005-1011.

59. Beigel J.H. 2012. Antiviral therapy (Non-HIV). In: Goldman's Cecil Medicine, 24th ed. Eds. Goldman L., Schafer A.I. Philadelphia: Elsevier.

60. Beck J., Vogel M., Nassal M. 2002. dNTP versus NTP discrimination by phenylalanine 451 in duck hepatitis $\mathrm{B}$ virus $\mathrm{P}$ protein indicates a common structure of the dNTP-binding pocket with other reverse transcriptases. Nucleic Acids Res. 30 (7), 1679-1687.

61. Langley D.R., Walsh A.W., Baldick C.J., Eggers B.J., Rose R.E., Levine S.M., Kapur A.J., Colonno R.J., Tenney D.J. 2007. Inhibition of hepatitis B virus polymerase by entecavir. J. Virol. 81 (8), 3992-4001. 
62. Seifer M., Hamatake R.K., Colonno R.J., Standring D.N. 1998. In vitro inhibition of hepadnavirus polymerases by the triphosphates of BMS-200475 and lobucavir. Antimicrob. Agents Chemother. 42 (12), 3200-3208.

63. Scott L.J., Keating G.M. 2009. Entecavir. Drugs. 69 (8), 1003-1033.

64. Ruiz-Sancho A., Sheldon J., Soriano V. 2007. Telbivudine: A new option for the treatment of chronic hepatitis B. Expert Opin. Biol. Ther. 7 (5), 751-761.

65. Denning J., Cornpropst M., Flach S.D., Berrey M.M., Symonds W.T. 2013. Pharmacokinetics, safety, and tolerability of GS-9851, a nucleotide analog polymerase inhibitor for hepatitis $\mathrm{C}$ virus, following single ascending doses in healthy subjects. Antimicrob. Agents Chemother. 57 (3), 1201-1208.

66. Murakami E., Tolstykh T., Bao H., Niu C., Steuer H.M.M., Bao D., Chang W., Espiritu C., Bansal S., Lam A.M., Otto M.J., Sofia M.J., Furman P.A. 2010. Mechanism of activation of PSI-7851 and its diastereoisomer PSI-7977. J. Biol. Chem. 285 (45), 34337-34347.

67. Asselah T. 2014. Sofosbuvir for the treatment of hepatitis C virus. Expert Opin. Pharmacother. 15 (1), 121130.

68. Fung A., Jin Z., Dyatkina N., Wang G., Beigelman L., Deval J. 2014. Efficiency of incorporation and chain termination determines the inhibition potency of 2 '-modified nucleotide analogs against hepatitis $\mathrm{C}$ virus polymerase. Antimicrob. Agents Chemother. 58 (7), 3636-3645.

69. Koch U., Narjes F. 2007. Recent progress in the development of inhibitors of the hepatitis C virus RNA-dependent RNA polymerase. Curr. Top. Med. Chem. 7 (13), 1302-1329.

70. Sheahan T.P., Sims A.C., Graham R.L., Menachery V.D., Gralinski L.E., Case J.B., Leist S.R., Pyrc K., Feng J.Y., Trantcheva I., Bannister R., Park Y., Babusis D., Clarke M.O., Mackman R.L., et al. 2017. Broad-spectrum antiviral GS-5734 inhibits both epidemic and zoonotic coronaviruses. Sci. Transl. Med. 9 (396), eaal3653.

71. Gordon C.J., Tchesnokov E.P., Woolner E., Perry J.K., Feng J.Y., Porter D.P., Götte M. 2020. Remdesivir is a direct-acting antiviral that inhibits RNA-dependent RNA polymerase from severe acute respiratory syndrome coronavirus 2 with high potency. J. Biol. Chem. 295 (20), 6785-6797.

72. Eastman R.T., Roth J.S., Brimacombe K.R., Simeonov A., Shen M., Patnaik S., Hall M.D. 2020. Remdesivir: A review of its discovery and development leading to emergency use authorization for treatment of COVID-19. ACS Cent. Sci. 6 (5), 672-683.

73. Ferner R.E., Aronson J.K. 2020. Remdesivir in covid-19. Br. Med. J. 369, m1610.

74. Gordon C.J., Tchesnokov E.P., Feng J.Y., Porter D.P., Götte M. 2020. The antiviral compound remdesivir potently inhibits RNA-dependent RNA polymerase from Middle East respiratory syndrome coronavirus. J. Biol. Chem. 295 (15), 4773-4779.

75. Muller W.E., Maidhof A., Taschner H., Zahn R.K. 1977. Virazole (1- $\beta$ - $D$-ribofuranosyl-1,2,4-triazole-3carboxamide); a cytostatic agent. Biochem. Pharmacol. 26 (11), 1071-1075.
76. Parker W.B. 2005. Metabolism and antiviral activity of ribavirin. Virus Res. 107 (2), 165-171.

77. Graci J.D., Too K., Smidansky E.D., Edathil J.P., Barr E.W., Harki D.A., Galarraga J.E., Bollinger J.M., Jr., Peterson B.R., Loakes D., Brown D.M., Cameron C.E. 2008. Lethal mutagenesis of picornaviruses with N-6modified purine nucleoside analogues. Antimicrob. Agents Chemother. 52 (3), 971-979.

78. Crotty S., Cameron C., Andino R. 2002. Ribavirin's antiviral mechanism of action: Lethal mutagenesis? J. Mol. Med. 80 (2), 86-95.

79. Crotty S., Maag D., Arnold J.J., Zhong W., Lau J.Y.N, Hong Z., Andino R., Cameron C.E. 2000. The broadspectrum antiviral ribonucleoside ribavirin is an RNA virus mutagen. Nat. Med. 6 (12), 1375-1379.

80. Wang M., Cao R., Zhang L., Yang X., Liu J., Xu M., Shi Z., Hu Z., Zhong W., Xiao G. 2020. Remdesivir and chloroquine effectively inhibit the recently emerged novel coronavirus (2019-nCoV) in vitro. Cell Res. 30 (3), 269-271.

81. Naesens L., Guddat L.W., Keough D.T., van Kuilenburg A.B.P., Meijer J., Voorde J.V., Balzarini J. 2013. Role of human hypoxanthine guanine phosphoribosyltransferase in activation of the antiviral agent T-705 (favipiravir). Mol. Pharmacol. 84 (4), 615-629.

82. Jin Z., Smith L.K., Rajwanshi V.K., Kim B., Deval J. 2013. The ambiguous base-pairing and high substrate efficiency of T-705 (favipiravir) ribofuranosyl 5'-triphosphate towards influenza A virus polymerase. PLoS One. 8 (7), e68347.

83. Baranovich T., Wong S.S., Armstrong J., Marjuki H., Webby R.J., Webster R.G., Govorkova E.A. 2013. T705 (favipiravir induces lethal mutagenesis in influenza A H1N1 viruses in vitro. J. Virol. 87 (7), 3741-3751.

84. Smee D.F., Hurst B.L., Egawa H., Takahashi K., Kadota T., Furuta Y. 2009. Intracellular metabolism of favipiravir (T-705) in uninfected and influenza $A$ (H5N1) virus-infected cells. J. Antimicrob. Chemother. 64 (4), 741-746.

85. U.S. Food and Drug Administration (fda.gov): FDAApproved Drugs, Clinical Trials. https://www. accessdata.fda.gov/ Accessed March 1, 2021.

86. DrugBank Database. Clinical Drug Data. https:// www.drugbank.com Accessed March 1, 2021.

87. Approved Antiviral Compounds and mechanisms Of Drug Actions of Approved Antiviral Drugs. http://virusface.com. Accessed March 1, 2021.

88. ChEMBL Database of Bioactive Molecules with Drug-like Properties. https://www.ebi.ac.uk/chembl/ Accessed March 23, 2021.

89. Database of privately and publicly Funded Clinical Studies Conducted around the World. https://clinicaltrials.gov/ Accessed March 1, 2021.

90. Suzuki M., Okuda T., Shiraki K. 2006. Synergistic antiviral activity of acyclovir and vidarabine against herpes simplex virus types 1 and 2 and varicella-zoster virus. Antiviral Res. 72 (2), 157-161.

91. Miwa N., Kurosaki K., Yoshida Y., Kurokawa M., Saito S., Shiraki K. 2005. Comparative efficacy of acyclovir and vidarabine on the replication of varicellazoster virus. Antiviral Res. 65 (1), 49-55. 
92. Hanes J.W., Zhu Y., Parris D.S., Johnson K.A. 2007. Enzymatic therapeutic index of acyclovir. Viral versus human polymerase gamma specificity. J. Biol. Chem. 282 (34), 25159-25167.

93. The DailyMed Database Containing Labeling, Submitted to the Food and Drug Administration (FDA) by Companies. https://dailymed.nlm.nih.gov/dailymed/ Accessed March 25, 2021.

94. Xiong X., Smith J.L., Kim C., Huang E.S., Chen M.S. 1996. Kinetic analysis of the interaction of cidofovir diphosphate with human cytomegalovirus DNA polymerase. Biochem. Pharmacol. 51 (11), 1563-1567.

95. Sergerie Y., Boivin G. 2008. Hydroxyurea enhances the activity of acyclovir and cidofovir against herpes simplex virus type 1 resistant strains harboring mutations in the thymidine kinase and/or the DNA polymerase genes. Antiviral Res. 77 (1), 77-80.

96. Yoshida Y., Honma M., Kimura Y., Abe H. 2021. Structure, synthesis and inhibition mechanism of nucleoside analogues as HIV-1 reverse transcriptase inhibitors (NRTIs). Chem. Med. Chem. 16 (5), 743-766.

97. Kukhanova M.K. 2012. Anti-HIV nucleoside drugs: A retrospective view into the future. Mol. Biol. (Moscow). 46 (6), 768-779.

98. Drabikowska A.K., Dudycz L., Shugar D. 1979. Studies on the mechanism of antiviral action of $1-(\beta-D-r i-$ bofuranosyl)-1,2,4-triazole-3-carboxamide (ribavirin). J. Med. Chem. 22 (6), 653-657.

99. Ortega-Prieto A.M., Sheldon J., Grande-Pérez A., Tejero H., Gregori J., Quer J., Esteban J.I., Domingo E., Perales C. 2013. Extinction of hepatitis C virus by ribavirin in hepatoma cells involves lethal mutagenesis. PLoS One. 8 (8), e 71039.

100. Sheu T.G., Deyde V.M., Okomo-Adhiambo M., Garten R.J., Xu X., Bright R.A., Butler E.N., Wallis T.R., Klimov A.I., Gubareva L.V. 2008. Surveillance for neuraminidase inhibitor resistance among human influenza A and B viruses circulating worldwide from 2004 to 2008. Antimicrob. Agents Chemother. 52 (9), 3284-3292.

101. Focher F., Lossani A., Verri A., Spadari S., Maioli A., Gambino J.J., Wright G.E., Eberle R., Black D.H., Medveczky P., Medveczky M., Shugar D. 2007. Sensitivity of monkey B virus (Cercopithecine herpesvirus L.) to antiviral drugs: Role of thymidine kinase in antiviral activities of substrate analogs and acyclonucleosides. Antimicrob. Agents Chemother. 51 (6), 2028-2034.

102. Seley-Radtke K.L., Yates M.K. 2018. The evolution of nucleoside analogue antivirals: A review for chemists and non-chemists: 1. Early structural modifications to the nucleoside scaffold. Antiviral Res. 154, 66-86.

103. Yates M.K., Seley-Radtke K.L. 2019. The evolution of antiviral nucleoside analogues: A review for chemists and non-chemists: 2. Complex modifications to the nucleoside scaffold. Antiviral Res. 162, 5-21.

104. Galegov G.A. 2017. Phosphazide (nikavir) is a highly effective drug for the treatment of HIV/AIDS infection. Vopr. Nirusol. 62 (1), 5-11.

105. McGuigan C., Pathirana R.N., Mahmood N., Devine K.G., Hay A.J. 1992. Aryl phosphate derivatives of AZT retain activity against HIV1 in cell lines which are resistant to the action of AZT. Antiviral Res. 17 (4), 311-321.

106. Cahard D., McGuigan C., Balzarini J. 2004. Aryloxy phosphoramidate triesters as pro-tides. Mini Rev. Med. Chem. 4 (4), 371-381.

107. Yeo K.L., Chen Y.L., Xu H.Y., Dong H., Wang Q.Y., Yokokawa F., Shi P.Y. 2015. Synergistic suppression of dengue virus replication using a combination of nucleoside analogs and nucleoside synthesis inhibitors. Antimicrob. Agents Chemother. 59 (4), 2086-2093.

108. Cho A., Zhang L., Xu J., Lee R., Butler T., Metobo S., Aktoudianakis V., Lew W., Ye H., Clarke M., Doerffler E., Byun D., Wang T., Babusis D., Carey A.C., et al. 2014. Discovery of the first $C$-nucleoside $\mathrm{HCV}$ polymerase inhibitor (GS-6620. with demonstrated antiviral response in $\mathrm{HCV}$ infected patients. J. Med. Chem. 57 (5), 1812-1825.

109. Siegel D., Hui H.C., Doerffler E., Clarke M.O., Chun K., Zhang L., Neville S., Carra E., Lew W., Ross B., Wang Q., Wolfe L., Jordan R., Soloveva V., Knox J., et al. 2017. Discovery and synthesis of a phosphoramidate prodrug of a pyrrolo [2,1-f][triazin-4-amino] adenine $C$-nucleoside (GS-5734) for the treatment of Ebola and emerging viruses. J. Med. Chem. 60 (5), 1648-1661.

110. Murakami E., Wang T., Babusis D., Lepist E.I., Sauer D., Park Y., Vela J.E., Shih R., Birkus G., Stefanidis D., Kim C.U., Cho A., Ray A.S. 2014. Metabolism and pharmacokinetics of the anti-hepatitis $\mathrm{C}$ virus nucleotide prodrug GS-6620. Antimicrob. Agents Chemother. 58 (4), 1943-1951.

111. Meier C. 2017. Nucleoside diphosphate and triphosphate prodrugs-an unsolvable task? Antiviral Chem. Chemother. 25 (3), 69-82.

112. Aggarwal S.K., Gogu S.R., Rangan S.R., Agrawal K.C. 1990. Synthesis and biological evaluation of prodrugs of zidovudine. J. Med. Chem. 33 (5), 1505-1510.

113. Morin K.W., Wiebe L.I., Knaus E.E. 1993. Synthesis of brain-targeted 1-(2-deoxy-2-fluoro- $\beta$ - $D$-ribofuranosyl)-(E)-5-(2-iodovinyl)uracil coupled to a dihydropyridine $\leftrightharpoons$ pyridinium salt redox chemical-delivery system. Carbohydr. Res. 249 (1), 109-116.

114. Kraevskii A.A. 1992. Search for new drugs for the treatment of HIV infections among nucleosides and nucleotides, II. Pharm. Chem. J. 26 (1), 33-47.

115. Esnouf R., Ren J., Ross C., Jones Y., Stammers D., Stuart D. 1995. Mechanism of inhibition of HIV-1 reverse transcriptase by non-nucleoside inhibitors. Nat. Struct. Biol. 2 (4), 303-308.

116. 2005. Nucleoside Triphosphates and Their Analogs: Chemistry, Biotechnology, and Biological Applications, 1st ed. Ed. Vaghefi M. Boca Raton, FL: CRC press.

117. Zhou Z., Liu T., Wu G., Kang D., Fu Z., Wang Z., De Clercq E., Pannecouque C., Zhan P., Liu X. 2019. Targeting the hydrophobic channel of NNIBP: Discovery of novel 1,2,3-triazole-derived diarylpyrimidines as novel HIV-1 NNRTIs with high potency against wildtype and K103N mutant virus. Org. Biomol. Chem. 17 (12), 3202-3217.

118. Kang D., Feng D., Sun Y., Fang Z., Wei F., De Clercq E., Pannecouque C., Liu X., Zhan P. 2020. Structurebased bioisosterism yields HIV-1 NNRTIs with im- 
proved drug-resistance profiles and favorable pharmacokinetic properties. J. Med. Chem. 63 (9), 4837-4848.

119. Kang D., Feng D., Ginex T., Zou J., Wei F., Zhao T., Huang B., Sun Y., Desta S., De Clercq E., Pannecouque C., Zhan P., Liu X. 2020. Exploring the hydrophobic channel of NNIBP leads to the discovery of novel piperidine-substituted thiophene[3,2-d]pyrimidine derivatives as potent HIV-1 NNRTIs. Acta Pharm. Sin. B. 10 (5), 878-894.

120. Jin K., Liu M., Zhuang C., De Clercq E., Pannecouque C., Meng G., Chen F. 2020. Improving the positional adaptability: Structure-based design of biphenyl-substituted diaryltriazines as novel non-nucleoside HIV-1 reverse transcriptase inhibitors. Acta Pharm. Sin. B. 10 (2), 344-357.

121. Wang Z., Kang D., Feng D., Cherukupalli S., Jiang X., Fu Z., De Clercq E., Pannecouque C., Liu X., Zhan P. 2020. Targeting dual tolerant regions of binding pocket: Discovery of novel morpholine-substituted diarylpyrimidines as potent HIV-1 NNRTIs with significantly improved water solubility. Eur. J. Med. Chem. 206, 112811.

122. Bressanelli S., Tomei L., Rey F.A., De Francesco R. 2002. Structural analysis of the hepatitis $C$ virus RNA polymerase in complex with ribonucleotides. J. Virol. 76 (7), 3482-3492.

123. Tomei L., Altamura S., Bartholomew L., Biroccio A., Ceccacci A., Pacini L., Narjes F., Gennari N., Bisbocci M., Incitti I., Orsatti L., Harper S., Stansfield I., Rowley M., De Francesco R., Migliaccio G. 2003. Mechanism of action and antiviral activity of benzimidazole-based allosteric inhibitors of the hepatitis $\mathrm{C}$ virus RNA dependent RNA polymerase. J. Virol. 77 (24), 13225-13231.

124. Chan L., Reddy T.J., Proulx M., Das S.K., Pereira O., Wang W., Siddiqui A., Yannopoulos C.G., Poisson C., Turcotte N., Drouin A., Alaoui-Ismaili M.H., Bethell R., Hamel M., L'Heureux L., et al. 2003. Identification of $N, N$-disubstituted phenylalanines as a novel class of inhibitors of hepatitis C NS5B polymerase. J. Med. Chem. 46 (8), 1283-1285.

125. Tomei L., Altamura S., Bartholomew L., Bisbocci M., Bailey, C., Bosserman M., Cellucci A., Forte E., Incitti I., Orsatti L., Koch U., De Francesco R., Olsen D.B., Carroll S.S., Migliaccio G. 2004. Characterization of the inhibition of hepatitis C virus RNA replication by nonnucleosides. J. Virol. 78 (2), 938946.

126. Chan L., Das S.K., Reddy T.J., Poisson C., Proulx M., Pereira O., Courchesne M., Roy C., Wang W., Siddiqui A., Yannopoulos C.G., Nguyen-Ba N., Labrecque D., Bethell R., Hamel M., et al. 2004. Discovery of thiophene-2-carboxylic acids as potent inhibitors of HCV NS5B polymerase and HCV subgenomic RNA replication: 1. Sulfonamides. Bioorg. Med. Chem. Lett. 14 (3), 793-796.

127. Chan L., Pereira O., Reddy T.J., Das S.K., Poisson C., Courchesne M., Proulx M., Siddiqui A., Yannopoulos C.G., Nguyen-Ba N., Roy C., Nasturica D., Moinet C., Bethell R., Hamel M., et al. 2004. Discovery of thiophene-2-carboxylic acids as potent inhibitors of HCV NS5B polymerase and HCV subgenomic RNA replication: 2. Tertiary amides. Bioorg. Med. Chem. Lett. 14 (3), 797-800.

128. Harper S., Avolio S., Pacini B., Di Filippo M., Altamura S., Tomei L., Paonessa G., Di Marco S., Carfi A., Giuliano C., Padron J., Bonelli F., Migliaccio G., De Francesco R., Laufer R., et al. 2005. Potent inhibitors of subgenomic hepatitis $\mathrm{C}$ virus RNA replication through optimization of indole- $N$-acetamide allosteric inhibitors of the viral NS5B polymerase. J. Med. Chem. 48 (14), 4547-4557.

129. Biswal B.K., Wang M., Cherney M.M., Chan L., Yannopoulos C.G., Bilimoria D., James M.N.G. 2006. Non-nucleoside inhibitors binding to hepatitis $\mathrm{C}$ virus NS5B polymerase reveal a novel mechanism of inhibition. J. Mol. Biol. 361 (1), 33-45.

130. Tatum H., Thuluvath P.J., Lawitz E., Martorell C., DeMicco M., Cohen S., Rustgi V., Ravendhran N., Ghalib R., Hanson J., Zamparo J., Zhao J., Cooney E., Treitel M., Hughes E. 2015. A randomized, placebocontrolled study of the NS5B inhibitor beclabuvir with peginterferon/ribavirin for HCV genotype 1. J. Viral Hepat. 22 (8), 658-664.

131. Toyota J., Karino Y., Suzuki F., Ikeda F., Ido A., Tanaka K., Takaguchi K., Naganuma A., Tomita E., Chayama K., Fujiyama, S., Inada Y., Yoshiji H., Watanabe H., Ishikawa H., et al. 2017. Daclatasvir/asunaprevir/beclabuvir fixed-dose combination in Japanese patients with HCV genotype 1 infection. J. Gastroenterol. 52 (3), 385-395.

132. Gentles R.G. 2019. Discovery of beclabuvir: A potent allosteric inhibitor of the hepatitis $\mathrm{C}$ virus polymerase. In: HCV: The Journey from Discovery to a Cure, vol. 1. Ed. Sofia M.J. Topics in Medicinal Chemistry. Cham: Springer, pp. 193-228.

133. Balzarini J., Pérez-Pérez M.J., San-Félix A., Schols D., Perno, C.F., Vandamme, A.-M., Camarasa, M.-J., De Clercq E. 1992. 2',5'-Bis- $O$-(tert-butyldimethylsilyl)-3'-spiro-5"-(4"-amino-1",2"-oxathiole-2",2"-dioxide)pyrimidine (TSAO) nucleoside analogues: Highly selective inhibitors of human immunodeficiency virus type 1 that are targeted at the viral reverse transcriptase. Proc. Natl. Acad. Sci. U. S. A. 89 (10), 43924396.

134. Balzarini J., Perez-Perez M.-J., San-Felix A., Velazquez S., Camarasa M.-J., De Clercq E. 1992. [2',5'-Bis-O-(tert-butyldimethylsilyl)]-3'-spiro-5"-(4"amino-1",2"-oxathiole-2",2"-dioxide. (TSAO) derivatives of purine and pyrimidine nucleosides as potent and selective inhibitors of human immunodeficiency virus type 1. Antimicrob. Agents Chemother. 36 (5), 1073-1080.

135. Balzarini J., Pérez-Pérez M.-J., San-Félix A., Camarasa M.-J., Bathurst I.C., Barr P.J., De Clercq E. 1992. Kinetics of inhibition of human immunodeficiency virus type 1 (HIV-1. reverse transcriptase by the novel HIV-1-specific nucleoside analogue [2', 5'-bis- $O$ - $($ tertbutyldimethylsilyl)- $\beta$-D-ribofuranosyl]-3'-spiro-5"(4"-amino-1",2"-oxathiole-2", 2"-dioxide)thymine (TSAO-T). J. Biol. Chem. 267 (17), 11831-11838.

136. Camarasa M.J., Pérez-Pérez M.J., Velázques S., SanFélix A., Alvarez R., Ingate S., Jimeno M.L., Karlsson A., De Clercq E., Balzarini J. 1995. TSAO derivatives: Highly specific inhibitors of human immunodeficien- 
cy virus type 1 (HIV-1. replication. Nucleosides, Nucleotides, Nucleic Acids. 14 (3-5), 585-594. https://doi.org/10.1080/15257779508012432

137. Balzarini J., Karlsson A., Vandamme A.-M., PérezPérez M.-J., Zhang H., Vrang L., Öberg B., Bäckbro K., Unge T., San-Félix A., Velázquez S., Camarasa M.-J., De Clercq E. 1993. Human immunodeficiency virus type $1(\mathrm{HIV}-1)$ strains selected for resistance against the HIV-l-specific [2',5'-bis- $O$-(tert-butyldimethylsilyl)3'-spiro-5"-(4"-amino-1",2"-oxathiole-2",2"-dioxide)]$\beta$-D-pentofuranosyl (TSAO) nucleoside analogues retain sensitivity to HIV-1-specific nonnucleoside inhibitors. Proc. Natl. Acad. Sci. U. S. A. 90 (15), 6952-6956.

138. Alvarez R., Jimeno M.-L., Pérez-Pérez M.-J., De Clercq E., Balzarini J., Camarasa M.-J. 1997. Synthesis and anti-human immunodeficiency virus type 1 activity of novel 3'-spiro nucleoside analogues of TSAO-T. Antivir. Chem. Chemother. 8 (6), 507-517.

139. Angusti A., Manfredini S., Durini E., Ciliberti N., Vertuani S., Solaroli N., Pricl S., Ferrone M., Fermeglia M., Loddo R., Secci B., Visioli A., Sanna T., Collu G., Pezzullo M., La Colla P. 2008. Design, synthesis and anti Flaviviridae activity of $\mathrm{N}^{6}-, 5^{\prime}, 3^{\prime}-\mathrm{O}$ - and $5^{\prime}, 2^{\prime}-\mathrm{O}-$ substituted adenine nucleoside analogs. Chem. Pharm. Bull. (Tokyo). 56 (4), 423-432.

140. De Burghgraeve T., Selisko B., Kaptein S., Chatelain G., Leyssen P., Debing, Y., Jacobs M., Van Aerschot A., Canard B., Neyts J. 2013. 3',5'Di- $O$-trityluridine inhibits in vitro flavivirus replication. Antiviral Res. 98 (2), 242-247.

141. Chatelain G., Debing Y., De Burghgraeve T., Zmurko J., Saudi M., Rozenski J., Neyts J., Van Aerschot A. 2013. In search of flavivirus inhibitors: Evaluation of different tritylated nucleoside analogues. Eur. J. Med. Chem. 65, 249-255.
142. Saudi M., Zmurko J., Kaptein S., Rozenski J., Neyts J., Van Aerschot A. 2014. In search of Flavivirus inhibitors: 2. Tritylated, diphenylmethylated and other alkylated nucleoside analogues. Eur. J. Med. Chem. 76, 98-109.

143. Vernekar S.K.V., Qiu L., Zhang J., Kankanala J., Li H., Geraghty R.J., Wang Z. 2015. 5'-Silylated 3'-1,2,3-triazolyl thymidine analogues as inhibitors of West Nile virus and dengue virus. J. Med. Chem. 58 (9), 40164028.

144. McGuigan C., Serpi M., Slusarczyk M., Ferrari V., Pertusati F., Meneghesso S., Derudas M., Farleigh L., Zanetta P., Bugert J. 2016. Anti-flavivirus activity of different tritylated pyrimidine and purine nucleoside analogues. ChemistryOpen. 5 (3), 227-235.

145. Eyer L., Nencka R., De Clercq E., Seley-Radtke K., Růžek D. 2018. Nucleoside analogs as a rich source of antiviral agents active against arthropod-borne flaviviruses. Antiviral Chem. Chemother. 26, 2040206618761299.

146. St.Vincent M.R., Colpitts C.C., Ustinov A.V., Muqadas M., Joyce M.A., Barsby N.L., Epand R.F., Epand R.M., Khramyshev S.A., Valueva O.A., Korshun V.A., Tyrrell D.L.J., Schang L.M. 2010. Rigid amphipathic fusion inhibitors, small molecule antiviral compounds against enveloped viruses. Proc. Natl. Acad. Sci. U. S. A. 107 (40), 17339-17344.

147. Orlov A.A., Chistov A.A., Kozlovskaya L.I., Ustinov A.V., Korshun V.A., Karganova G.G., Osolodkin D.I. 2016. Rigid amphipathic nucleosides suppress reproduction of the tick-borne encephalitis virus. Med. Chem. Comm. 7 (3), 495-499.

148. Strasfeld L., Chou S. 2010. Antiviral drug resistance: Mechanisms and clinical implications. Infect. Dis. Clin. North Am. 24 (2), 413-437.

Translated by A. Ostyak 